\title{
Solving Civil Engineering Problems by Means of Fuzzy and Stochastic MCDM Methods: Current State and Future Research
}

\author{
Jurgita Antucheviciene, ${ }^{1}$ Zdeněk Kala, ${ }^{2}$ Mohamed Marzouk, ${ }^{3}$ and Egidijus Rytas Vaidogas ${ }^{4}$ \\ ${ }^{1}$ Department of Construction Technology and Management, Faculty of Civil Engineering, Vilnius Gediminas Technical University, \\ Saulètekio Aleja 11, LT-10223 Vilnius, Lithuania \\ ${ }^{2}$ Department of Structural Mechanics, Faculty of Civil Engineering, Brno University of Technology, Veveři Street 95, \\ 60200 Brno, Czech Republic \\ ${ }^{3}$ Department of Structural Engineering, Faculty of Engineering, Cairo University, Giza 12613, Egypt \\ ${ }^{4}$ Department of Labour Safety and Fire Protection, Faculty of Civil Engineering, Vilnius Gediminas Technical University, \\ Sauletekio Alèja 11, LT-10223 Vilnius, Lithuania \\ Correspondence should be addressed to Jurgita Antucheviciene; jurgita.antucheviciene@vgtu.lt
}

Received 9 May 2015; Accepted 11 June 2015

Academic Editor: Peide Liu

Copyright (C) 2015 Jurgita Antucheviciene et al. This is an open access article distributed under the Creative Commons Attribution License, which permits unrestricted use, distribution, and reproduction in any medium, provided the original work is properly cited.

\begin{abstract}
The present review examines decision-making methods developed for dealing with uncertainties and applied to solve problems of civil engineering. Several methodological difficulties emerging from uncertainty quantification in decision-making are identified. The review is focused on formal methods of multiple criteria decision-making (MCDM). Handling of uncertainty by means of fuzzy logic and probabilistic modelling is analysed in light of MCDM. A sensitivity analysis of MCDM problems with uncertainties is discussed. An application of stochastic MCDM methods to a design of safety critical objects of civil engineering is considered. Prospects of using MCDM under uncertainty in developing areas of civil engineering are discussed in brief. These areas are design of sustainable and energy efficient buildings, building information modelling, and assurance of security and safety of built property. It is stated that before long the decision-making in civil engineering may face several methodological problems: the need to combine fuzzy and probabilistic representations of uncertainties in one decision-making matrix, the necessity to extend a global sensitivity analysis to all input elements of a MCDM problem with uncertainties, and an application of MCDM methods in the areas of civil engineering where decision-making under uncertainty is presently not common.
\end{abstract}

\section{Introduction}

Decision-making is applied in different areas of human activities. In the case of existence of at least two possible options, a person (i.e., a decision-maker) has to make a decision and to select the one which is best suited for his demands. Complex problems in science, engineering, technology, or management are characterised by multiple criteria. Usually they are hardly measurable, conflicting or interacting with each other. Decision-making (DM) problems based on multiple criteria are objects of MCDM.

MCDM is a discipline concerned with the theory and methodology for handling problems common in everyday life. They arise in such areas as business, engineering, social organisation, and so forth [1]. MCDM has grown as a part of operation research pertaining to the design of computational and mathematical tools for supporting the subjective evaluation of performance criteria by decision-makers [2].

As it is mentioned in a review paper [3], the origins of MCDM methods can be dated over 270 years ago. As an individual scientific discipline, MCDM has been widely spreading since the middle of the previous century. Numerous works on MCDM are summarized in a number of review papers [4]. Three main types of review papers related to MCDM can be distinguished: reviews of developments and extensions of a particular method (e.g., [5]) as well as its applications (e.g., [6,7]); reviews of different approaches to modern MCDM methods (e.g., DM under uncertain and 


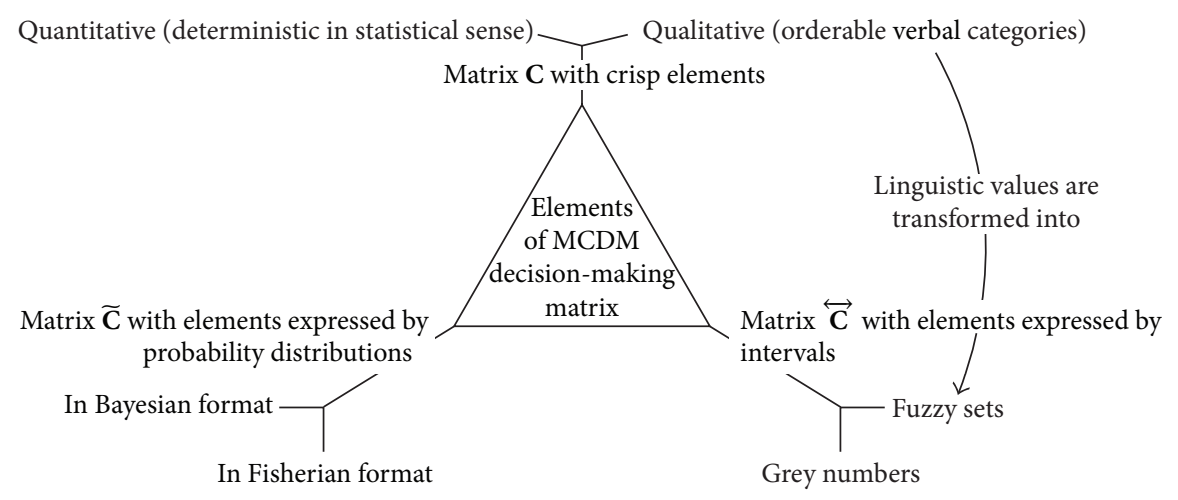

FIGURE 1: The main types of criteria used to construct the decision-making matrix of MCDM.

incomplete information and DM for groups of persons $[2,8]$ ); reviews of applications of different MCDM methods for a particular problem [9-11].

Most, if not all, decisions in engineering are made under uncertainty. Accordingly, classical crisp methods, involving deterministic conditions under certain decision environments, are losing their relevance and new extensions for handling various types of uncertainties in MCDM problems appear. In most cases, uncertain elements of MCDM problems express subjective expert opinions and less often they represent stochastic nature of input data. Understanding the significance and impact of different types of uncertainties in input information and its relation to reality can increase the quality of DM process.

The present review strives to examine the current state of uncertainty modelling in MCDM and to identify several problems which decision-makers may face in the immediate future. The review is organized as follows. Section 2 presents the scope of the review and identifies several problems related to MCDM under uncertainty. Section 3 presents the latest references on applications of MCDM approaches in uncertain decision environments of civil engineering. Section 4 summarizes the applications of sensitivity analysis (SA) in fuzzy and stochastic MCDM techniques. Section 5 analyses published work on introducing measures of risk and reliability in the MCDM related to civil engineering. Section 6 attempts to identify the need for future research. This section presents a brief discussion on potential applications of MCDM under uncertainty in the areas which currently receive much attention in research and practice. Finally, conclusions and prospective research trends are presented in Section 7.

\section{The Scope of the Review}

Generally, a MCDM problem is defined as follows. Let $\mathbf{a}=$ $\left(a_{1}, a_{2}, \ldots, a_{i}, \ldots, a_{m}\right)^{\mathrm{T}}$ be a vector of decision alternatives and $\mathbf{c}=\left(c_{1}, c_{2}, \ldots, c_{j}, \ldots, c_{n}\right)$ a set of criteria, according to which suitability of alternatives $a_{i}$ is to be judged. The problem is stated as a $m \times n$ decision-making matrix $\mathbf{C}$ with the elements $c_{i j}$. The value $c_{i j}$ expresses an impact of the criterion $c_{j}$ on the alternative $a_{i}$. Values of $\mathrm{c}$ related to the alternatives $a_{i}$ are the row vectors $c_{i}=\left(c_{i 1}, c_{i 2}, \ldots, c_{i j}, \ldots, c_{i n}\right)$ and, with these vectors, the matrix $\mathbf{C}$ is formulated as $\left[\mathbf{c}_{1}, \mathbf{c}_{2}, \ldots, \mathbf{c}_{j}, \ldots, \mathbf{c}_{m}\right]^{\mathrm{T}}$. In many MCDM methods, the importance of the criteria $c_{j}$ is expressed by the weights $w_{j}$ which sum up to unity and are usually grouped into the vector $\mathbf{w}=\left(w_{1}, w_{2}, \ldots, w_{j}, \ldots, w_{n}\right)$. The purpose of DM is to determine the most preferable alternative among $a_{i}$ with respect to all criteria or to rank the alternatives. The result of ranking is expressed by a preference sequence, for example, $\pi: a_{x}>a_{y}>a_{z}>\cdots$.

A large variety of MCDM methods have been developed to date. A universal and comprehensive classification of these methods does not exist. For the purposes of the present review, MCDM methods will be classified according to the nature of the criteria grouped into the decision-making matrix $\mathbf{C}$ (Figure 1). In the previous five decades, a development of MCDM was focused mainly on solving MCDM problems with crisp elements of C. In parallel with this process, fuzzy MCDM methods have been developed since 1970s [12]. These methods allow solving MCDM problems with a decision-making matrix $\overleftrightarrow{\mathbf{C}}$, the elements of which are modelled by fuzzy sets. Development and application of fuzzy MCDM methods significantly increased during the last two-three decades. One of the possible representations of $c_{i j}$ by fuzzy sets is grey numbers based on interval arithmetic. Several recent publications devoted to a use of grey numbers for decision-making in engineering can be cited here [1315]. Finally, in the recent time, several MCDM methods were created and applied to a solution of decision-making problems, in which elements of $\mathbf{C}$ are modelled by means of probability distributions. Such a matrix will be denoted by the symbol $\widetilde{\mathbf{C}}$.

The fact that until now uncertainties in MCDM problems were expressed in several different ways generates a problem of choosing among these possibilities. Further problems related to handling uncertainties in decision-making are illustrated in Figure 2. A decision-maker having to rank the alternatives $a_{i}$ in the presence of uncertainties may face the following problems:

(1) The problem of choice among different representations of uncertainty related to criteria values $c_{i j}$ and weights $w_{j}$. 


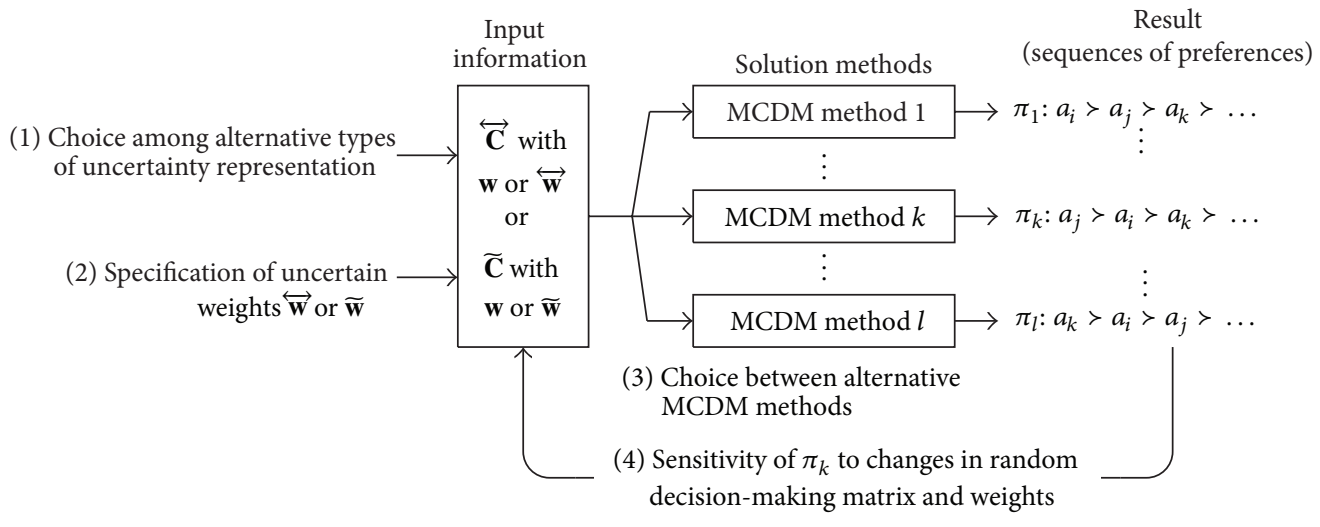

FIGURE 2: Four problems related to handling uncertainties in MCDM.

(2) Specification of the weights $w_{j}$ in the case where they are uncertain quantities.

(3) The problem of choice among available MCDM methods for solving a problem with the decision-making matrices $\overleftrightarrow{\mathbf{C}}$ or $\widetilde{\mathbf{C}}$.

(4) Analysis of sensitivity of MCDM results to the changes in all elements of input data given by the matrices $\overleftrightarrow{\mathbf{C}}$ or $\widetilde{\mathbf{C}}$ and the vectors $\mathbf{w}, \overleftrightarrow{\mathbf{w}}$, or $\widetilde{\mathbf{w}}$. Input uncertainties can cause possible permutations in the sequences of preferences, $\pi_{k}$, obtained by means of a specific MCDM method $k$.

The first problem has its origin "outside" the domain of MCDM. Discussions of the type "fuzzy versus probabilistic" or "nonprobabilistic versus probabilistic" last many years and do not seem to be finished until now (e.g., [16]). In most applications of MCDM under uncertainty, authors do not trouble themselves to explain why a particular method of uncertainty quantification was preferred over others. The fuzzy logic prevails over probabilistic modelling by the number of MCDM methods developed to date and the number of MCDM applications to practical problems. Currently, one can state the obvious that probability distributions can be specified in Fisherian format for $c_{i j}$ in the presence of sufficient amount of statistical data on $c_{i j}$. A representation of $c_{i j}$ by fuzzy sets is better suited for $c_{i j}$ expressing subjective expert opinions. However, it is important to remember that the Bayesian approach to probabilistic modelling has excellent means of quantifying and updating subjective judgments (e.g., [17]). This approach does not break down when data on $c_{i j}$ is sparse or absent. MCDM problems can be solved when uncertainties in $c_{i j}$ are represented in any of the aforementioned formats. A true problem will arise when the decision-making matrix will be a "mixture" of the elements $c_{i j}$ expressed by different means of uncertainty quantification, probabilistic and nonprobabilistic.

The second problem of specifying elements of the vector of weights, w, is obviously an "internal" problem of MCDM. There is a body of literature devoted to specifying values of $w_{j}$. Methods used to determine criteria weights are classified into subjective, objective, and hybrid or integrated ones [1820]. However, the task of assigning specific values to the components $w_{j}$ will always be subjective or at least partly subjective, no matter what is the degree of mathematical sophistication behind this assignment. A really intriguing question is how $w_{j}$ can be interpreted as uncertain quantities. The experts who usually specify the values of $w_{j}$ can be uncertain (vague) regarding their opinions on $w_{j}$. Should weights be modelled by a fuzzy vector $\overleftrightarrow{\mathbf{w}}$ or a vector $\widetilde{\mathbf{w}}$ with components expressed by probability distributions?

The third problem reflects the well-known decisionmaking paradox which was first identified by Triantaphyllou and Mann in 1989 [21]. The paradox was exhibited by many MCDM methods developed to deal with the crisp decisionmaking matrix C. Switching to uncertain matrices $\overleftrightarrow{\mathbf{C}}$ or $\widetilde{\mathbf{C}}$ will not resolve this paradox. It will be likely to persist also in the field of decision-making under uncertainty. The present review will not address this tricky issue.

The fourth problem arises naturally, because a MCDM method is in essence a mathematical model relating the input information expressed by $\mathbf{C}$ and $\mathbf{w}$ to the output information given by the preference sequence $\pi$. A sensitivity of $\pi$ to changes in elements of $\mathbf{C}$ and $\mathbf{w}$ can be estimated (analysed) by standard mathematical means of general use. However, a sensitivity analysis (SA) of a MCDM problem with uncertain matrices $\overleftrightarrow{\mathbf{C}}$ or $\widetilde{\mathbf{C}}$ and/or uncertain vectors $\overleftrightarrow{\mathbf{w}}$ or $\widetilde{\mathbf{w}}$ is a nontrivial task.

The four problems of MCDM under uncertainty listed and briefly discussed above are of methodological nature. This kind of DM can face also problems of different nature, namely, an application in such areas of civil engineering as development of sustainable and energy efficient buildings, building information modelling, assurance of security, and safety of built property. Solving MCDM problems in these areas will face the necessity to model uncertainties related to long-term predictions, vague information available in the process of building design, and possibility of rare but extremely damaging events. A particular need for modelling uncertainties in MCDM problems arises at a design of safety critical objects of civil engineering. Failures of such objects or damage to them can cause severe consequences to 
society and environment. Many of safety critical objects are assessed (designed) by applying methods of reliability theory or probabilistic risk assessment. Measures of reliability and components of risk estimates can be uncertain quantities. An application of MCDM to the design of safety critical objects requires including these quantities into the decision-making matrix C. In most cases, uncertainties related to reliably and risk are modelled by means of probability distributions. Therefore, the decision-making matrix will be formulated as the matrix $\widetilde{\mathbf{C}}$. A combination of SA and MCDM applied to the design of the safety critical objects will allow revealing the most important MCDM criteria related to safety.

The following sections of this review will consider the problems raised above in greater detail. The attention will be focused on both results achieved until now and problematic issues which may require attention in the future.

\section{MCDM Techniques under Uncertainty in Civil Engineering}

Decision-making in the field of civil engineering is increasingly complex and is associated with situations where robust decisions are required to be taken. These decisions are made in different stages of civil engineering projects. For example, decision-making takes place during feasibility study stage prior to design, procurement, and construction stages in order to determine the viability of project undertaken by an investor. Also it often faces the need to deal with hazardous phenomena, including industrial accidents able to damage built property, structural failures, extreme natural phenomena, and human acts affecting security. Proper decisions made by architects and civil engineers may reduce the risk posed by the aforementioned phenomena.

Decision-making in this field can be facilitated by an application of formal methods, such as methods of multiple criteria decision-making. Factors relevant to decisions can be identified using the methods of uncertainty and SA of mathematical model outputs.

The result of the evaluation of an alternative according to a given criteria is a single value (e.g., number or verbal expressions) for unambiguous deterministic information. For ambiguous information, the result of the evaluation of variants according to a given criteria is a random variable if the information is stochastic in nature or a fuzzy variable if the information is nonstochastic in nature. The stochastic nature of a phenomenon is associated with the unlimited repeatability of the phenomenon. Unrepeatable phenomena or phenomena with uncertain knowledge significance are nonstochastic in nature.

3.1. Fuzzy MCDM. The fuzzy framework is the most common approach to describe and handle uncertainty in MCDM. Considering the imprecisions and uncertainties, that is, fuzziness of the available data and the decision-making procedures, fuzzy set theory can be applied [22]. In a fuzzy MCDM, the elements $c_{i j}$ of $\mathbf{C}$ are characterised by fuzzy sets. In what follows, such elements will be denoted by the symbol $\overleftrightarrow{c_{i j}}$ and a decision-making matrix containing fuzzy elements will be $\overleftrightarrow{\mathbf{C}}$. The fuzzy set theory can be used for a MCDM, whenever probability distributions of $c_{i j}$ are unknown due to lack of statistical data or there is no wish to express subjective judgments about values of $c_{i j}$ in a probabilistic way. The weights $w_{j}$ can also be modelled as fuzzy variables $\overleftrightarrow{w_{j}}$ and so the vector $\mathbf{w}$ can be a fuzzy one, $\overleftrightarrow{\mathbf{w}}$.

In MCDM problems, three types of fuzziness can be observed: the ratings of each alternative with respect to each criterion are uncertain or imprecise and weights are crisp numbers $\left(\overleftrightarrow{c_{i j}}, w_{j}\right)$; the ratings of alternatives are crisp numbers while fuzzy numbers are used to assess the weights of all criteria $\left(c_{i j}, \overleftrightarrow{w_{j}}\right)$; both the ratings and the weights are fuzzy $\left(\overleftrightarrow{c_{i j}}, \overleftrightarrow{w_{j}}\right)$. Each type of uncertainty has its own characteristics and is appropriate for special cases.

A lot of fuzzy extensions of MCDM methods have been proposed and applied in engineering, technology, or management. Fuzzy extensions of MCDM involve application of basic fuzzy logic, using triangular fuzzy numbers and arithmetic operations, also trapezoidal fuzzy numbers, as well as intuitionistic fuzzy relations, interval-valued intuitionistic fuzzy relations, type- 2 fuzzy sets, and hesitant fuzzy sets concepts. Nonfuzzy uncertain decision methods include reliability theory and probabilistic and grey-valued formulations for handling incomplete or imprecise information. The most widely applied fuzzy extensions of MCDM methods are fuzzy AHP (analytic hierarchy process), with the origins dated to 1983 [23] and various numerous extensions of fuzzy TOPSIS (technique for order preference by similarity to ideal solution) $[2,24]$. Several latest extensions of more recently developed methods are worth to be mentioned: extension of weighted aggregated sum product assessment in an intervalvalued intuitionistic fuzzy environment (WASPAS-IVIF) [25], a complex proportional assessment method extended with interval-valued intuitionistic fuzzy numbers (COPRASIVIF), and suitable for group decision-making [26]. The most recent extended versions of MULTIMOORA (multiobjective optimization by ratio analysis plus full multiplicative form) utilize the basic fuzzy logic $[27,28]$ or are based on the interval 2-tuple linguistic variables [29], intuitionistic fuzzy numbers [30], or hesitant fuzzy numbers [31]. ARAS under fuzzy environment was also presented [32] and further applied [33, 34].

Numerous researches utilize not a single fuzzy MCDM (FMCDM) method but combine several of the methods. Two groups of researches can be distinguished: either integrating two or more available techniques and proposing so-called hybrid methods or employing several methods for a solution of a problem and comparing ranking results. The study [2] reviews papers on development and applications of MCDM during the last two decades by various aspects. The analysis covers 1081 papers related to MCDM and fuzzy MCDM. While a detailed survey is made on 403 papers published in peer review journals and entirely devoted to fuzzy decisions, involving 217 papers in a field of engineering, it is obvious that engineering applications cover over 50 percent of overall applications. Accordingly, it can be stated that fuzzy MCDM 


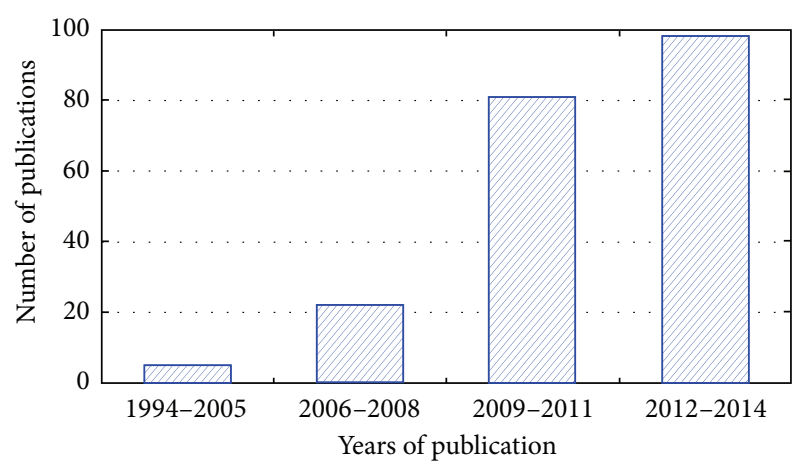

FIGURE 3: Increase of FMCDM applications in engineering.

is useful and applicable technique for complex decisionmaking in civil engineering under uncertainty.

The increasing importance of the methods can be based on the findings that the number of developments and applications is increasing every year. On the basis of collected data [2], annual distribution of papers in engineering field is explored. The period is divided into several stages. The first stage covers 1994-2005, when a number of papers are small or even absent in certain years. The later period starting from 2006, when a number of researches began increasing, is grouped in three years. A chart (Figure 3) shows increase of FMCDM applications in engineering, measured by a number of publications included in the review paper [2] on FMCDM techniques and applications during two decades.

The last period from the above four covers 46 percent of publications issued during 20 years. The largest number of researches on the whole is observed in 2014.

The latest FMCDM approaches are applied in various subfields of civil engineering field. Subfields which are the most numerously supported by considered approaches are related to sustainability and building lifecycle assessment, supply chain management in construction, technology and inventory selection in construction industries, location selection and infrastructure modelling, and knowledge management.

Environmental, social and economic aspects of sustainable building were incorporated when evaluating mining projects and their impact on environment [35], assessing building energy performance [36] or performance of pavements with emphasis on sustainability [37].

Supply chain management is handled through proper supplier selection considering multiple criteria simultaneously. Various approaches are applied for supplier evaluation and selection, starting from the most common fuzzy AHP and hybrid methods integrating AHP and TOPSIS [38], AHP and PROMETHEE [39], and so forth. Also novel extensions based on interval type-2 fuzzy sets [40] or intuitionistic fuzzy information [41] are utilized.

Selection of technologies, inventory, or materials in construction is also widely supported by FMCDM. Examples of the most recent applications are for selecting material handling equipment $[42,43]$, inventory classification [44], and selection of robots for automated technology operations [45].
Fuzzy decision-making methods are extremely important for handling vagueness in special-purpose building projects and their location. Fuzzy multiple criteria approaches successfully applied for nuclear power plant site selection [46], deep-water see port selection [47], and health monitoring of tunnels [48].

Regarding DM methodology in civil engineering applications, it can be concluded that the most common approach is observed to be fuzzy AHP-TOPSIS hybrid technique [38, 49], also combining fuzzy AHP with other classical methods as PROMETHEE [50] and DEMATEL [51, 52].

Another group of researches applies several FMCDM methods simultaneously and compares ranking results. An example can be provided of material selection applying a number of hybrid approaches, namely, FAHP-VIKOR, FAHPPROMETHEE, FAHP-TOPSIS, and FAHP-ELECTRE [53], technology selection applying FAHP, TOPSIS-F, VIKOR-F, and COPRAS-G [45], and so forth.

3.2. Stochastic MCDM. The probabilistic framework is the second approach to describe and handle uncertainty in MCDM. In this framework, the elements $c_{i j}$ of the decisionmaking matrix $\mathbf{C}$ are modelled by random variables $\tilde{c}_{i j}$ expressing uncertainty in possible values of $c_{i j}$. The uncertainty is quantified by means of probability distributions which can be specified in the format Fisherian or Bayesian statistics. Presence of $\widetilde{c}_{i j}$ in $\mathbf{C}$ generates a matrix $\widetilde{\mathbf{C}}$, all or some elements of which are random. Stochastic MCDM methods are used to solve the decision problems with the matrix $\widetilde{\mathbf{C}}$.

MCDM solved with an emphasis on stochastic uncertainty (SMCDM) is focused on decision problems of the selection of alternatives from several criteria that are mathematically described neither as crisp numbers nor as fuzzy numbers or linguistic variables but as random variables [54]. Stochastic methods for the determination of weights from various types of information on the character of the significance of criteria are effectively implemented especially in the AHP method. The classical AHP method lacks probability values for the distinction of adjacent alternatives in the final ranking [55]. Vargas [56] considered the case where members of the pairwise comparison matrix were random variables.

It should be noted that although random variables are considered, purely stochastic uncertainty of input data and decision-making procedures is rare. The occurrence of a random phenomenon is almost always accompanied by a certain degree of personal belief; therefore, the term subjective probability is sometimes used. The reason for the implementation of random variables in MCDM is the attempt to use methods of the theory of probability and mathematical statistics for the analysis of uncertainty of the results of the decision-making process. Advanced methods of stochastic $\mathrm{SA}$, the equivalent of which is unknown in fuzzy MCDM, are available for stochastic MCDM [57].

There are numerous SMCDM methods and applications in real world situations $[58,59]$. The classical Monte Carlo (MC) method or its improved variants can be used to tackle most SMCDM problems $[60,61]$. The theoretical application of the Monte Carlo method is very extensive; however, 
the results of stochastic analysis are very sensitive to the laws of probability density functions and type of dependencies between input variables resulting in fuzzy (epistemic) uncertainty in decision-making tasks. Analysis of forecast uncertainty based on fuzzy stochastic approaches and its application to a number of problems in civil engineering and related fields is described in detail, for example, in the book [62]. However, the complexity of mathematical approaches and the interpretation of results limit the scientific ingenuity of the application of fuzzy stochastic SA methods.

\section{Sensitivity Analysis Applied to MCDM}

Two types of SA are most often mentioned in the literature: local SA and global SA (e.g., [63, 64]). Local SA determines a contribution of a given input parameter of a mathematical model to its output. Local methods do not attempt to fully explore the input parameter space. They examine small perturbations, usually one parameter at a time. Global SA examines a mathematical model in the presence of uncertain input parameters. SA of this type apportions output uncertainty to different sources of uncertainty in the input. Input and output uncertainties are expressed by probability distributions. Global SA applies perturbations of the entire space of input parameters. It is also argued that global SA should be used "in tandem" with uncertainty analysis and the latter should precede the former in practical applications [65, 66]. The aim of uncertainty analysis is to estimate variation in model output and SA apportions this variation to input parameters.

Local SA was applied in the recent past for better understanding of MCDM methods. Global SA was used for improving models which are related MCDM but do not fit strictly into its scheme. MCDM constitutes a special class of mathematical models. An application of SA to MCDM rises specific problems. However, any methodological specificity of performing SA for applications of MCDM in civil engineering is not known to us. In addition, combined applications of MCDM and SA to problems of civil engineering are few in number and deal mainly with selecting locations of buildings [67, 68]. A certain relation to civil engineering has applications of combined MCDM and SA to geographic information systems (see Malczewski and Rinner [69] and references cited therein). Therefore, the remainder of this section will be a general discussion on SA applications to a better understanding of MCDM methods.

\subsection{Applications of SA in Deterministic MCDM and MCDM} under Uncertainty. In the light of the aforementioned SA definitions, a deterministic (crisp) MCDM method can be interpreted as follows: elements of the matrix $\mathbf{C}$ and components of the vector $\mathbf{w}$ represent input parameters, the preference sequence $\pi$ is model output, and the procedure relating $\pi$ to $\mathbf{C}$ and $\mathbf{w}$ is a mathematical model. A sensitivity of $\pi$ versus $\mathbf{C}$ and $\mathbf{w}$ is called ranking sensitivity or sensitivity to ranking stability (e.g., $[70,71])$. With the deterministic input $\mathbf{C}$ and $\mathbf{w}$, a sensitivity of $\pi$ versus $\mathbf{C}$ and $\mathbf{w}$ can be determined by means of local SA methods.
Triantaphyllou and Sánchez applied local SA to determine the criterion $c_{j}$ and the decision matrix element $c_{i j}$ which is most critical to the ranking expressed by $\pi[72$, 73]. They applied sensitivity measures based on minimum changes in the weights $w_{j}$ and matrix elements $c_{i j}$ which cause changes between ranks of the alternatives $a_{i}$. Bevilacqua and Braglia used a simple wide-range variation of the weights $w_{j}$ to explore shifts in the ranking $\pi$ obtained by means of a deterministic AHP [74]. Any numerical sensitivity measure or graphical representation of SA results was not suggested in this study. Chang et al. and Wu et al. carried out SA of AHP results based on increasing values of $w_{j}$ up to $35 \%$ $[67,75]$. They expressed SA results graphically. This approach was applied to SA of results obtained with fuzzy decisionmaking matrix $\overleftrightarrow{\mathbf{C}}$ [71]. The results were produced by means of fuzzy TOPSIS and fuzzy AHP methods.

Another kind of perturbations used to reveal sensitivity of $\pi$ versus $w_{j}$ is exchanging positions of the weights within the vector w. Choudhary and Shankar used such perturbations for results obtained with a combined fuzzy AHP and TOPSIS method [76]. A total of $n_{p}$ perturbations produces a set of preference sequences $\pi_{p}\left(p=1,2, \ldots, n_{p}\right)$ which are treated as SA result and expressed graphically. In a series of methodologically similar articles, Awasthi et al. suggested using the sequences $\pi_{p}$ for a final ranking of the alternatives $a_{i}[68,77-79]$. The sequences $\pi_{p}$ were obtained for a problem with fuzzy weights $\overleftrightarrow{\mathbf{w}}$ and fuzzy matrix $\overleftrightarrow{\mathbf{C}}$. The alternatives $a_{i}$ were ranked by counting scores for each $a_{i}$ according to its position in $\pi_{p}$. These authors also tried to use this scoring for a qualitative assessment of ranking sensitivity. However, any quantitative sensitivity measure was not suggested.

A quantitative measure of ranking sensitivity used in several studies is known as an average shift in ranks (ASR). Some of these studies fit into the scheme of MCDM and some have common elements with this field. In line with the notations used herein, ASR is expressed as the mean $m^{-1} \sum_{i=1}^{m}\left|r_{i}^{\varsigma}-r_{i}^{\mathrm{ref}}\right|$, where $r_{i}^{\varsigma}$ is the rank of the alternative $a_{i}$ related to a perturbation $\varsigma$ and $r_{i}^{\text {ref }}$ is the rank of $a_{i}$ in a reference (base) ranking. Saisana et al. used ASR as a model output for a global SA [80]. ASR was computed on the basis of a composite indicator. The reference ranks $r_{i}^{\text {ref }}$ were obtained from one specific application of the indicator. Ben-Arieh used ASR in the format of MCDM for sort of a local SA [81]. ASR was applied to pairwise comparisons of alternative rankings obtained with different linguistic quantifiers (probabilities). They were used for calculating the weights $w_{j}$. The ranks $r_{i}^{\varsigma}$ and $r_{i}^{\text {ref }}$ were obtained using pairs of different linguistic quantifiers. Later on, the same approach was used by other authors for assessing ranking sensitivity to fuzzy linguistic quantifiers [82-84]. ASR was applied also to a global SA related to MCDM. Ligman-Zielinska suggested using ASR as a scalar representation of output ranking and computing a sensitivity index based on variance of ASR [65]. Unfortunately, values of ASR depend on the choice of the reference ranks $r_{i}^{\text {ref }}$ and this introduces certain arbitrariness in the process of SA. Apart from ASR, an alternative and well-elaborated scalar measure expressing a sensitivity of 
permutations within $\pi$ to input of MCDM models is not known to us.

4.2. Sensitivity to Model Selection. One of the key problems of MCDM is a selection of method (model) relating input information expressed by $\mathbf{C}$ and $\mathbf{w}$ to the output ranking sequence $\pi$. If the MCDM method requires normalisation of the initial matrix $\mathbf{C}$, the analyst will also face the problem of choosing among several normalisation rules (formulas) (e.g., [85]). Using different normalisation rules may also contribute to the variability of ranks within the sequence $\pi$.

An application of fuzzy numbers as elements of the matrix $\overleftrightarrow{\mathbf{C}}$ and components of the vector $\overleftrightarrow{\mathbf{w}}$ will introduce an additional problem of model selection. Membership functions of fuzzy numbers, $\mu_{\overleftrightarrow{w_{j}}}\left(w_{j}\right)$ and $\mu_{c_{i j}}\left(c_{i j}\right)$, may not necessarily be triangular as in the most fuzzy MCDM applications (Links 1 and 2, Figure 4). The choice of the type of fuzzy numbers in $\overleftrightarrow{\mathbf{C}}$ and components of the vector $\overleftrightarrow{\mathbf{w}}$ is a subjective exercise and introduces arbitrariness into MCDM process. Similar statements can be made about the use of random variables in $\widetilde{\mathbf{C}}$ and $\widetilde{\mathbf{w}}$. A specification of MCDM model input will require selecting specific types of probability densities $f_{\widetilde{c}_{i j}}\left(c_{i j} \mid \mu_{i j}, \sigma_{i j}\right)$ and $f_{\widetilde{w}_{j}}\left(w_{j} \mid \alpha_{j}, \beta_{j}\right)$ for decision matrix elements $\widetilde{c}_{i j}$ and criteria weights $\widetilde{w}_{j}$ (Links 3 and 4 , Figure 4 ). In case of $\widetilde{w}_{j}$, the selection of distribution type and then specification of its parameters $\alpha_{j}$ and $\beta_{j}$ will be purely subjective task. However, in some cases, statistical data on the random components $\widetilde{c}_{i j}$ of $\widetilde{\mathbf{C}}$ can be available. In such cases, distribution type of $\widetilde{c}_{i j}$ will be dictated by this data. Consequently, we can speak about three SA problems:

(1) Sensitivity of the ranking sequence $\pi$ to the selection of MCDM method.

(2) Sensitivity of $\pi$ to the choice of normalisation rule.

(3) Sensitivity of $\pi$ to the selection of membership function type in case of fuzzy MCDM and probability density type in case of stochastic MCDM.

The first two problems will be present in both deterministic MCDM and MCDM under uncertainty. The third problem will arise with the need to introduce uncertainties in MCDM process. To the best of our knowledge, a systematic, in-depth solution of these three problems is not available in the MCDM literature to date.

Apart from model selection problem, the use of the membership functions $\mu_{\overleftrightarrow{w_{j}}}\left(w_{j}\right)$ and $\mu_{\overleftrightarrow{c_{i j}}}\left(c_{i j}\right)$ and the density functions $f_{\widetilde{c}_{i j}}\left(c_{i j} \mid \mu_{i j}, \sigma_{i j}\right)$ and $f_{\widetilde{w}_{j}}\left(w_{j} \mid \alpha_{j}, \beta_{j}\right)$ will give rise to a problem of assessing sensitivity of the ranking sequence $\pi$ to parameters of these functions (Links 5 to 8, Figure 4). An association of all or some $w_{j}$ and $c_{i j}$ with two or more parameters of membership function or density function may substantially increase the dimensionality of input space. This can encumber SA process, especially in case of global SA. It will be necessary to assign additional distributions to this parameter in order to carry out Monte Carlo analysis of a MCDM model under study.

\section{Measures of Risk and Reliability in the MCDM Related to Civil Engineering}

Civil engineering systems can be damaged by deliberate assaults, actions induced during industrial accidents and extremes of nature. Damage to components of civil engineering systems induces mechanical and thermal actions called often abnormal or accidental ones. Incidents with abnormal actions are relatively rare, short-lasting, and usually unexpected events. They can cause serious harm and sometimes catastrophic consequences [86]. In terms of civil engineering, such incidents are called "abnormal situations" or "accidental situations." The latter term is used in the widely known standards ISO 2394 and ENV 1991-1. An adequate design of civil engineering systems for abnormal situations will result in resilient buildings and infrastructure able to avoid or absorb damage without undergoing a complete failure [8789].

5.1. MCDM and Safety in Civil Engineering. The design of components of safety critical civil engineering systems for abnormal situations requires, among other things, comparing alternative design solutions of these components. In terms of MCDM, they can be called alternative designs or simply alternatives $a_{i}(i=1,2, \ldots, m)$. Interalternative comparisons of $a_{i}$ must include criteria $c_{i j}$ expressing safety of $a_{i}$ or, alternatively, risk posed by $a_{i}$. The row vector of criteria, $\mathbf{c}_{i}=\left(c_{i 1}, c_{i 2}, \ldots, c_{i j}, \ldots, c_{i n}\right)$, will include also elements which are not necessarily related to safety, for instance, economic, functional, and aesthetic criteria.

The adequacy of the design of critical objects of civil engineering for abnormal situations is assured by applying methods of reliability theory and probabilistic risk assessment (PRA) [90]. These two fields of engineering are closely related and the criteria $c_{i j}$ can be specified by applying methods developed in each of them.

Values of $c_{i j}$ can be probabilities of failure or quantitative estimates of risk related to the designs $a_{i}$ [91]. Practical applications of MCDM to the design for abnormal situations will face the problem of uncertainty related to failure probabilities and risk estimates. Quantitative measures of this uncertainty can be introduced into MCDM problems. A wellestablished platform of uncertainty modelling in PRA is the Bayesian statistical theory or, in brief, the Bayesian approach [92]. In line with this approach, the uncertainty in potential safety-related criteria $c_{i j}$ is divided into two kinds: stochastic (aleatory) and state-of-knowledge (epistemic) uncertainty [93-96]. Uncertainties of either kind can be accommodated in MCDM problems.

5.2. An Integration of Reliability Measures and Related Quantities into MCDM. A failure probability $p_{\mathrm{f} i}$ characterising a particular alternative design $a_{i}$ can be used as a MCDM criterion $c_{i j}[85,91]$. A value of the failure probability $p_{\mathrm{f} i}$ assigned to the alternative $a_{i}$ accounts for the possibility of its potential failures. The probability $p_{\mathrm{f} i}$ can be "mechanically" included into a MCDM problem as one of components of the vector $\mathbf{c}_{i}$. However, in many cases the probabilities $p_{\mathrm{f} i}$ will be uncertain in the epistemic sense. The uncertainty in $p_{\mathrm{f} i}$ 


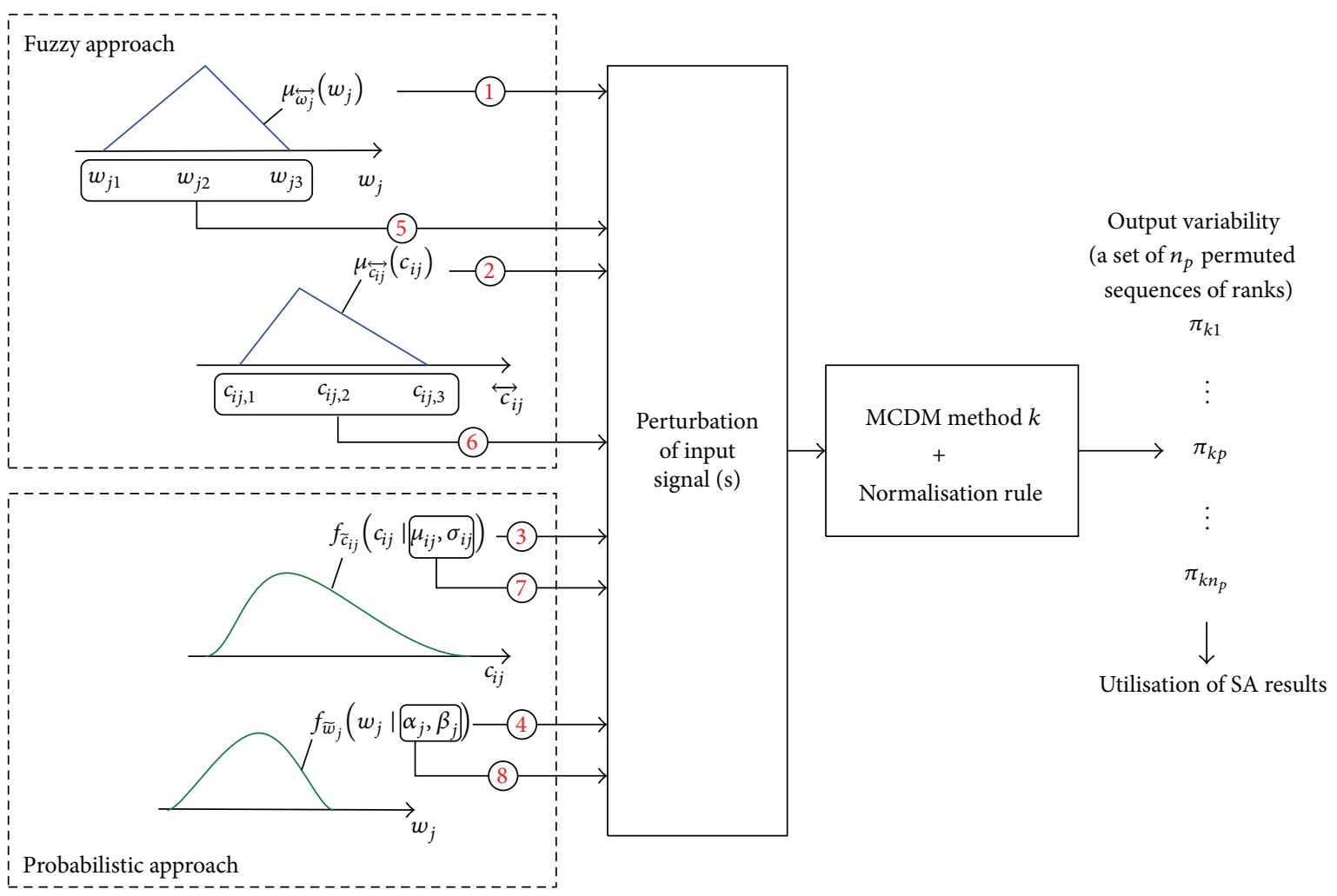

FIGURE 4: Possible SA links related to the input space of a MCDM problem and a specific MCDM method.

may stem primarily from sparse information on accidental actions. Quantitatively this uncertainty can be expressed by modelling the probabilities $p_{\mathrm{f} i}$ as epistemic random variables $\widetilde{p}_{\mathrm{f} i}$ [97]. If the uncertain failure probability $\widetilde{p}_{\mathrm{f} i}$ of $a_{i}$ is taken as a MCDM criterion, the vectors $\mathbf{c}_{i}$ will contain at least one random component and can be replaced by the stochastic vectors $\widetilde{\mathbf{c}}_{i}$ given by $\left(\widetilde{p}_{\mathrm{f} i 1}, \widetilde{p}_{\mathrm{f} i 2}, \ldots, \widetilde{p}_{\mathrm{f} i k_{i}}, c_{k_{i}+1}, c_{k_{i}+2}, \ldots, c_{i n}\right)$, where $k_{i}$ is the number of failure modes of $a_{i}$. Some or all criteria in the vector just mentioned can be uncertain in the stochastic (aleatory) sense. For instance, such criteria can be time of construction or cost of $a_{i}$. Uncertainty related to the stochastic components of $\widetilde{\mathbf{c}}_{i}$ can be expressed by the random variables $\widetilde{c}_{i j}$. With the random vectors $\widetilde{\mathbf{c}}_{i}$, a MCDM problem will have to be solved by applying a decision-making matrix $\widetilde{\mathbf{C}}$ some or all elements of which are random variables. Stochastic MCDM methods must be applied to deal with the matrix $\widetilde{\mathbf{C}}$

Vaidogas and Zavadskas suggested introducing the failure probabilities $p_{\mathrm{f} i l}\left(1 \leq l \leq k_{i}\right)$ into a MCDM problem indirectly, through comparison of the total (life-cycle) utilities $u_{\text {tot }, i}$ related to the alternatives $a_{i}$ [91]. The utility $u_{\text {tot, } i}$ is expressed as a difference between expected benefit from $a_{i}$ and a total cost of $a_{i}$. The failure probabilities $p_{\mathrm{f} i l}$ are incorporated into the total cost of $a_{i}$ through the cost of failures expressed by the sum $\sum_{l=1}^{k_{i}} p_{\mathrm{f} i l} c_{\mathrm{fl}}$, where $c_{\mathrm{fl}}$ is the anticipated cost of failure according to the failure mode $l$.

Vaidogas et al. applied reliability-oriented MCDM for a selection among alternative construction projects of a building [85]. Reliability of the alternative projects $a_{i}$ was expressed as a probability that a specified construction time will not be exceeded. A further application of MCDM was a ranking of designs of a reinforced concrete slab with different floorings. Probabilities of two failure modes of the slab were used as the criteria $c_{i j}$ : probability of collapse and probability of excessive deflection.

5.3. An Integration of Risk Estimates into MCDM. The alternatives $a_{i}$ can represent hazardous industrial objects which pose risk to people and environment in the form of industrial accidents. The magnitude of consequences of such accidents can range between minor and catastrophic consequences [98]. In the European Union, most of hazardous objects are regulated by Seveso Directives (currently Seveso III Directive) [99]. Such objects are assessed by means of formal methods developed in the field of PRA $[93,100]$.

A risk related to the design $a_{i}$ is a very informative characteristic suitable for inclusion into a MCDM problem [98]. In line with PRA, the risk related to $a_{i}$ is expressed by the set $\left\{\left(\lambda_{i s}, c_{i s}, \mathbf{m}_{i s}\right), s=1,2, \ldots, n_{a i}\right\}$, in which $\lambda_{i s}$ and $c_{i s}$ are likelihood-consequence pairs, $\mathbf{m}_{i s}$ are the vectors of magnitudes (severities) of $c_{i s}$, and $n_{a i}$ is the number of accident scenarios related to $a_{i}$. The vector $\mathbf{m}_{i s}$ is given by a certain number $n_{s}$ of magnitudes $m_{i s j}\left(j=1,2, \ldots, n_{s}\right)$. Zavadskas and Vaidogas suggested expressing the criteria $c_{i j}$ in the form of expected magnitudes $\bar{m}_{i j}$ [97]. The component $c_{i j}$ of the decision-making matrix $\mathbf{C}$ represented by $\bar{m}_{i j}$ is computed as the sum $\sum_{s=1}^{n_{a i}} \lambda_{i s} m_{i s j}$. 
As in the case of uncertain failure probabilities $\widetilde{p}_{\mathrm{f} i}$, the likelihoods $\lambda_{i s}$ can be uncertain quantities modelled by epistemic random variables $\tilde{\lambda}_{i s}$. In most instances, the variables $\tilde{\lambda}_{i s}$ will represent uncertain annual frequencies of the consequences $c_{i s}$. The presence of the random likelihood $\tilde{\lambda}_{i s}$ will stochastise the expected severities $\bar{m}_{i j}$ and they will turn into random variables, for example, $\widetilde{\bar{m}}_{i j}$. Consequently, a MCDM problem will turn into a stochastic one with a random decision-making matrix $\widetilde{\mathbf{C}}$. The row $\widetilde{\mathbf{c}}_{i}$ of $\widetilde{\mathbf{C}}$ will be expressed as $\left(\widetilde{\bar{m}}_{i 1}, \widetilde{\bar{m}}_{i 2}, \ldots, \widetilde{\bar{m}}_{i n_{s}}, c_{i, n_{s}+1}, c_{i, n_{s}+2}, \ldots, c_{i n}\right)$ with $n-$ $n_{s} \geq 1$, where the components denoted by the letter " $c$ " can be either deterministic or stochastically uncertain quantities. With the vectors $\widetilde{\mathbf{c}}_{i}$ including the risk-related components $\widetilde{\bar{m}}_{i j}$, the matrix $\widetilde{\mathbf{C}}$ can be expressed as a two-block matrix $\left[\begin{array}{l|l}\widetilde{\mathbf{C}}_{1} & \mathbf{C}_{2}\end{array}\right]$. The $m \times n_{s}$ matrix $\widetilde{\mathbf{C}}_{1}$ reflects risk estimates of the alternatives $a_{i}$, whereas the $m \times\left(n-n_{s}\right)$ matrix $\mathbf{C}_{2}$ includes criteria which are not directly related to the risk. Stochastic MCDM methods will be necessary to solve the MCDM problem with the matrix $\left[\widetilde{\mathbf{C}}_{1} \mid \mathbf{C}_{2}\right]$.

Vaidogas and Šakenaite applied the risk-based MCDM to a choice among alternative sprinkler systems [101]. Zhou et al. used a safety-oriented MCDM for solving decision-making problems of hydropower construction project management [102]. Catrinu and Nordgård applied PRA and MCDM to a management of electricity distribution system asset [103].

In recent years, a fairly large number of publications considered an application of MCDM methods for handling managerial risk related to construction projects and running built facilities. Although risk of this type differs by nature from the "pure" risk posed by (to) physical objects, assessments of managerial and "pure" risk are related through a need to deal with uncertainties in risky objects or processes. Nieto-Morote and Ruz-Vila used fuzzy AHP method for assessing building projects and selection of contractors [104, 105]. Xiang et al. applied fuzzy AHP for assessing risk arising at a construction of submerged floating tunnels [106]. Wang et al. used AHP in combination with other decision-making methods to assess risk posed by exploitation of bridges [107]. El-Abbasy et al. applied AHP method together with Monte Carlo simulation for selecting contractors of a highway project [108]. The studies just listed involve elements of a nonprobabilistic uncertainty quantification based on fuzzy sets. As the "pure" risk is always a part of managerial risk, uncertain criteria $\widetilde{c}_{i j}$ specified by means of probabilistic methods of PRA can be included into the decision matrix $\mathbf{C}$ alongside with "fuzzy" criteria $\overleftrightarrow{c_{i j}}$. However, MCDM methods which allow a simultaneous juggling of "probabilistic" and "fuzzy" criteria $\widetilde{c}_{i j}$ and $\overleftrightarrow{c_{i j}}$ do not exist at present, to the best of our knowledge.

5.4. MCDM and Fire Protection of Civil Engineering Objects. Fire is a prevailing hazard in most objects of civil engineering. Fire accidents often occur on construction sites $[109,110]$. As regards fire protection, MCDM methods were used until now mainly for ranking attributes expressing fire safety of completed buildings. AHP method was applied for developing weights of fire safety attributes in the socalled Edinburgh study [111]. A stochastic AHP was used by Zhao et al. to rank attributes of building fire safety [112]. Wong et al. used attributes of fire detection and alarm systems among a fairly large number of characteristics of an intelligent building. They applied two MCDM methods, AHP and ANP, to rank these characteristics [113, 114]. Vaidogas and Šakenaite formulated a number of MCDM problems, in which building fire safety is considered with respect to economics of fire protection: selection among existing buildings, building projects, and construction materials [115]. Vaidogas and Linkute considered also problems of decisionmaking in the design of structures used for protection of built property against accidental explosions [116].

\section{MCDM in Innovative Areas of Civil Engineering: A Look at Decision-Making under Uncertainty}

6.1. Developing Sustainable and Energy Efficient Building. Sustainability is a natural subject of MCDM, because it automatically includes three subsets of criteria, involving economics, environmental, and social aspects. When solving problems of sustainable building, the fourth subset of criteria, involving engineering-technological dimensions, is also necessary. One of the innovative themes in sustainable construction is related to using materials of low embodied energy and energy efficient applications. However, such things as future and real building cost, environmental impact, and future social status of a constructed facility are very uncertain if considered in a long sight. For instance, large built areas in Hamburg (Germany) lost a lot of image due to a social downgrade of inhabitants. Also a lot of industrial and farming buildings having perfect infrastructure were left abandoned due to political and respective economic changes in postSoviet states in Eastern Europe [117]. These buildings and territories make a great potential for further redevelopment as the recent trends in construction emphasize rehabilitation instead of occupying new territories, wasting building materials, and so forth. Building rehabilitation should be performed in accordance with principles of sustainable development, thus combining a number of usually conflicting and hardly measurable aspects.

The usefulness and even necessity of application of decision-making methods under uncertainty for aforementioned problems are summarized below. It is worth mentioning that DM under uncertainty is more characteristic to rehabilitation than to new construction. New construction is more regulated by technical norms, standards, and comprehensive planning. However, aspiration to redevelop a building in the most proper way is certainly a multiple criteria DM problem. Problem related to upgrading abandoned or depreciated buildings as well as physically and morally deteriorated built environment can generate several potential alternatives as demolishing depreciated building and building new structures (technically sound approach but contradicting to principles of sustainability), dismantling, reusing, or recycling of building materials (partly meeting principles of sustainability), renewal according to up-to-date requirements and using a building for previous purposes, 
or upgrading a building with intention to use for other purpose (e.g., conversion of industrial buildings to commercial or apartments). When searching for the best alternative solution from several potential decision alternatives $a_{i}$, a set of criteria $c_{j}$ should be defined and the matrix $\mathbf{C}$ can be formulated. The main challenge is in setting criteria values $c_{i j}$ related to the alternatives $a_{i}$ and criteria relative significances expressed by the weights $w_{j}$.

The four problems related to uncertainty measures could be identified. The first group of criteria has to assess features of building or surrounding environment, regional peculiarities using hardly measurable, vague, or incomplete data. Examples of criteria associated with vague, incomplete, or hardly measurable information, having no fixed values or expressed by linguistic scale, are architectural or historical value of a building (in terms of importance of preserving a building or its elements in a time of redevelopment), aesthetic appearance of a building and harmony with the environment after implementing a specific upgrading alternative, reflection of period norms, technologies, and so forth (in a case of upgrading vernacular buildings to contemporary building norms [14]). Examples of criteria associated with varying information, either related to a specific terms of a particular project or based on periodical or territorial measures, and expressed as interval data are building redevelopment costs (depending on particular material costs, labour costs in a locality, tax rates, etc.), energy savings (embodied energy, different technologies, and varying costs of energy), material and foreign investments in the area, changes in level of unemployment of local population or population activity index, and characterising social-economic value of a civil engineering project. The aforementioned uncertainty could be determined as fuzziness and managed with the help of fuzzy sets. Then, the elements $c_{i j}$ of $\mathbf{C}$ are characterised by fuzzy sets and denoted as $\overleftrightarrow{c_{i j}}$. In that case, a decision-making matrix containing fuzzy elements $\overleftrightarrow{\mathbf{C}}$ could be composed.

Another group of criteria should assess development possibilities and should be able to reflect probable changes over the time, involving long-term prediction. Examples of criteria could be risk related to political and respective economic changes, technology innovations in civil engineering and related areas, state/region business foresights, cash flow and net present value of a potential civil engineering project, life quality parameters and a real value of a building, state income from business, and property taxes, and so forth. In the current case, risk factors should be taken into account and probabilistic modelling should be applied when the elements $c_{i j}$ of the decision-making matrix $\mathbf{C}$ are modelled by random variables $\widetilde{c}_{i j}$ expressing uncertainty in criteria values, usually in Fisherian or Bayesian format. A matrix $\widetilde{\mathbf{C}}$ is subject to stochastic DM.

The third problem is based on combination of rather different criteria into a single solution. Combination of criteria is analysed in two senses. At first, a problem is in establishing relative significances of criteria in a particular task, based on decision-makers' preferences and peculiarities of the analysed problem. It is usually rather subjective and uncertain process. How could you compare significance of a local (e.g., cost of thermal insulation material) and a global criterion (e.g., energy savings, $\mathrm{CO}_{2}$ emissions, and their impact on global warming) for different stakeholders? How could you express uncertain or linguistic decisionmakers' preferences in a numerical format? What could be better specification of the weights $w_{j}$ in the case they are of uncertain quantities: $\overleftrightarrow{\mathbf{w}}$ or $\widetilde{\mathbf{w}}$ ?

The next issue as the fourth problem is combining fuzzy and stochastic uncertainties in a single task. Based on the above assumptions on criteria $\overleftrightarrow{c_{i j}}$ and $\widetilde{c}_{i j}$ as well as relative significances of criteria $(\overleftrightarrow{\mathbf{w}}$ or $\widetilde{\mathbf{w}})$, there is the need to combine fuzzy and probabilistic representation of uncertainties in one initial decision-making matrix. Next comes the problem of choice among available MCDM methods or their extensions to be able to deal with fuzzy and stochastic data simultaneously. Thus, development of sustainable construction can be solved adequately by combining fuzzy and probabilistic representation of uncertainties, applying MCDM methods able to deal with fuzzy and stochastic input data, and including SA, that is, analysing effect related to the input data on the optimal solution of a MCDM problem.

6.2. Possibilities to Apply MCDM Methods within BIM Process. Building information modelling (BIM) goes through a series of levels of development (LODs) which represent an increasing level of detailing [118, 119]. The "fuzzy" detailing in such levels as LOD100 or LOD200 naturally introduces uncertainties in a DM process. They must be taken into account as long as MCDM is applied in this early design stage.

In the context of building design organised as a successive passing of LODs, a comparison of the alternatives $a_{i}$ will make sense if $a_{i}$ will represent the same LOD. In principle, branching of the design process into the alternatives $a_{i}$ is possible on the conceptual level LOD100, as long as it is possible to characterise the vague information expressed by conceptual designs by some qualitative or quantitative criteria $c_{j}$. Most of them will express subjective opinions of architect and client, because very little can be measured quantitatively and objectively at this stage. This may require to express the opinions by fuzzy numbers or probability distributions and to solve a MCDM problem with respective matrices $\overleftrightarrow{\mathbf{C}}$ and $\widetilde{\mathbf{C}}$.

Higher levels of detail represented by LODs from 200 to 400 give better opportunity to formulate and solve a MCDM problem. Branching of the design process into the alternatives $a_{i}$ can be done on each of these levels. However, uncertainties may still be present because the designs will not be fully finished. Some characteristics of $a_{i}$ will be uncertain independently of available LOD. For instance, the final and precise construction cost and duration related to $a_{i}$ will be known only after completion of construction process.

A development of a large number of the alternatives $a_{i}$ and characteriation of each of them by the criteria $c_{j}$ can encumber the design process. In essence, a solution of a MCDM problem will require to prepare $m$ different designs of building related to the LOD reached in the design process. Thus, one can say that there is a "mega-uncertainty" related to 
the number of LODs at which an application of MCDM will be most efficient.

6.3. Deciding on Security and Safety of Buildings. Security and safety are things and activities which are done in order to keep people and organisation safe from attack, harm, and damage. Three primary areas of security are physical security, information security, and personnel security [120]. Safety is achieved by protecting objects of civil engineering against fire, lightning, earthquakes, extreme winds, and contamination events which can negatively affect indoor air quality.

Measures and procedures of physical security are used to improve protection of an organisation against threats and vulnerabilities. Physical security of built property includes elements related to civil engineering: access control, barriers, doors, fencing, perimeter security, vaults, walls, and windows. Physical security is also interrelated with safety of built property. Malicious acts of people committed outside or inside perimeters of built objects may not only induce structural damage but also cause severe harm to their occupants. Examples of such acts are bombings, shootings, deliberate vehicular impacts, and arsons. The saddest events of this kind are September 11 attacks on the world trade centre in New York.

A higher investment in security systems may reduce damaging potential of malicious acts. If such acts will happen in spite of all security measures, damage caused by them can be limited by a better design for safety. Such design involves architectural and structural solutions enhancing safety and provision of better safety systems (alarms, fire and evacuation control systems, monitors of indoor air, etc.). Effectiveness of security and safety can be characterised by at least two MCDM criteria (one for security and one for safety). Further criteria related to them may be costs of security and safety systems. We can add criteria which measure impact of architectural and structural solutions on security and safety. Presence of a number of criteria makes out a case for an application of MCDM to design of buildings with respect to security and safety.

In a MCDM oriented towards security and safety, the alternatives $a_{i}$ may represent different configurations of physical security systems and different solutions of safety systems. The alternatives $a_{i}$ can also represent different architectural and structural solutions influencing security and safety. New structural solutions of tall buildings suggested since September 11 can serve as an example [121]. The architectural and structural solutions may seriously influence security and safety. For instance, a low-rise building provides better opportunities for escape from fire and firefighting than a tall one. However, a low-rise building will have much longer external perimeter to be guarded than a tall building with the same floor area. On the other hand, a tall building is a better target for shooting or an attack by a plane.

A simultaneous consideration of security and safety as well as architectural and structural aspects in the same MCDM problem may pose also several problems at generating the set of $a_{i}$. The number of $a_{i}$ can be large due to a wide variety of security and safety systems available on the market. This number can be also increased by a large number of architectural and design solutions of the same building. A generation of the alternatives $a_{i}$ can be influenced by legal and regulatory restrictions which must be regarded simultaneously at a formulation of the designs represented by $a_{i}$.

The criteria $c_{j}$ used for evaluating the alternative triplets security-safety-architecture can be simple: amount and cost security equipment, number of security personnel, number of escape roots, minimum distance from a guarded object at which unauthorised persons must be stopped, and so forth. Such criteria are obvious and their values can be specified with relative ease. However, they do not reflect in-depth effectiveness of security and safety systems.

The effectiveness of safety systems can be expressed by applying methods of PRA as discussed in Section 5.2. Safety related criteria $c_{j}$ can be either likelihood or expected severities of accident scenarios. These accidents can be initiated by security breaches. For instance, an arsonist, after an unauthorised access to secured areas of a building, can initiate fires in different places. They will lead to different fire scenarios. The higher is an estimated level of safety and robustness of the building represented by $a_{i}$, and the smaller should be likelihood and consequences of potential accidents. The possibility of different accident scenarios does not allow to measure the level of safety by a single MCDM criterion.

The effectiveness of a physical security system can also be expressed by several criteria $c_{j}$ reflecting different identifiable scenarios of security breach. Examples of such scenarios are unauthorised access to secured areas, armed attack from outside of object perimeter, an attempt to hit a protected object with a vehicle, external disruption of power supply, and gas attack from outside the building. As in the case of PRA, likelihood measures can be estimated and consequences of security breaches assessed. The likelihood and consequence severities can be used as MCDM criteria $c_{j}$. The higher is level of physical security, and the smaller must be values of such criteria.

Attacks and adverse physical events impairing security and safety of built property are in most cases rare events. Data on such events is generally sparse. Therefore, estimating the likelihood of security and safety events will almost inevitably face the problem of quantifying epistemic uncertainties in the manner of PRA. This will lead to an inclusion of uncertain criteria into MCDM which are uncertain in the epistemic sense. In other words, problems of MCDM, in which security and safety of built property are regarded, can be solved adequately by composing the random decisionmaking matrix $\widetilde{\mathbf{C}}$.

\section{Conclusions}

In this review, methods developed for making decisions under uncertainty in civil engineering were examined. Along with this examination, several problems arising from dealing with uncertainties in decision-making were identified. The decision-making based on formal methods of MCDM was in the focus of the review. The prevailing two types of uncertainty quantification in MCDM rest on fuzzy logic and 
probabilistic modelling. The need to introduce uncertainty modelling into MCDM exists in many areas of civil engineering. A proper handling of such uncertainties will require solving several methodological problems: specification of fuzzy and random decision-making matrices, analysis of sensitivity of MCDM results to changes in all elements of an initial MCDM problem, and the need to combine fuzzy and random criteria in the same decision-making task. MCDM under uncertainty is quite flexible methodology. It can be applied in areas of civil engineering which are currently under development and receive much attention in research.

A certain challenge to MCDM is sensitivity analysis. Various techniques of local sensitivity analysis were applied until now to explore MCDM methods applied in various fields. These applications deal mainly with sensitivity of MCDM output versus values of weights. Applications of global sensitivity analysis to MCDM are not numerous, despite the fact that analysis of this type is very popular in general science. These applications deal mainly with geographic information systems.

A partially unresolved issue in applications of sensitivity analysis to MCDM is how to represent sequences of alternative rankings by scalar variables. Currently, the only suggestion is to use for this purpose a quantity known as average shift in ranks. MCDM raises a sensitivity analysis problem characteristic to this methodology, namely, sensitivity to model selection. Ranking of alternatives could vary at choosing different MCDM methods and normalisation formulas. An additional model selection problem will arise at choosing the type of fuzzy numbers and probability distributions used for modelling input variables of a MCDM problem. At present, a clear and comprehensive answer to the issue of sensitivity to model selection in MCDM does not exist.

The need for modelling uncertainties can be particularly high in applications of MCDM to a design of safety critical objects. Damage to such objects may cause severe consequences. Safety critical objects can be assessed by means of reliability theory and probabilistic risk analysis. Measures of reliability and risk estimates are usually uncertain quantities. In terms of risk analysis, this uncertainty is called epistemic (state-of-knowledge) uncertainty. Epistemic uncertainties related to reliability and risk are modelled by means of probability distributions. An application of MCDM to the design of safety critical objects will require including epistemic random variables into a decision-making matrix of a MCDM problem. Probabilistic risk estimates can be elements of a broader class of risk known as business or managerial risk. A decision-making with respect to this kind of risk may require formulating and solving MCDM problems involving two types of uncertainties. Decision-making matrices of such problems will involve elements modelled by both fuzzy sets and probability distributions. Therefore, there is a need to develop MCDM methods allowing dealing with two different types of uncertainty in one decision-making problem.

MCDM under uncertainty has prospects to be intensively applied in such areas as development of sustainable and energy efficient buildings, building information management, and assurance of security and safety of built property. Decision-making in these areas faces large uncertainties related to long-term predictions, vague information on buildings under design, and rare and unexpected extreme events. Methods of fuzzy and stochastic MCDM can facilitate making decisions in the areas just mentioned.

\section{Conflict of Interests}

The authors declare that there is no conflict of interests regarding the publication of this paper.

\section{Acknowledgment}

The part of the paper done by the author from Czech Republic has been worked out under Project no. LO1408 "AdMAs UP."

\section{References}

[1] M. M. Wiecek, M. Ehrgott, G. Fadel, and J. R. Figueira, "Multiple criteria decision making for engineering," Omega, vol. 36, no. 3, pp. 337-339, 2008.

[2] A. Mardani, A. Jusoh, and E. K. Zavadskas, "Fuzzy multiple criteria decision-making techniques and applicationstwo decades review from 1994 to 2014," Expert Systems with Applications, vol. 42, no. 8, pp. 4126-4148, 2015.

[3] J. J. H. Liou and G.-H. Tzeng, "Comments on 'Multiple criteria decision making (MCDM) methods in economics: an overview,' Technological and Economic Development of Economy, vol. 18, no. 4, pp. 672-695, 2012.

[4] E. K. Zavadskas, Z. Turskis, and S. Kildiene, "State of art surveys of overviews on MCDM/MADM methods," Technological and Economic Development of Economy, vol. 20, no. 1, pp. 165-179, 2014.

[5] T. Baležentis and A. Baležentis, "A survey on development and applications of the multi-criteria decision making method MULTIMOORA," Journal of Multi-Criteria Decision Analysis, vol. 21, no. 3-4, pp. 209-222, 2014.

[6] M. Behzadian, R. B. Kazemzadeh, A. Albadvi, and M. Aghdasi, "PROMETHEE: a comprehensive literature review on methodologies and applications," European Journal of Operational Research, vol. 200, no. 1, pp. 198-215, 2010.

[7] M. Behzadian, S. Khanmohammadi Otaghsara, M. Yazdani, and J. Ignatius, "A state-of the-art survey of TOPSIS applications," Expert Systems with Applications, vol. 39, no. 17, pp. 13051-13069, 2012.

[8] R. Ureña, F. Chiclana, J. A. Morente-Molinera, and E. HerreraViedma, "Managing incomplete preference relations in decision making: a review and future trends," Information Sciences, vol. 302, no. 1, pp. 14-32, 2015.

[9] J. Chai, J. N. K. Liu, and E. W. T. Ngai, "Application of decisionmaking techniques in supplier selection: a systematic review of literature," Expert Systems with Applications, vol. 40, no. 10, pp. 3872-3885, 2013.

[10] G. Kabir, R. Sadiq, and S. Tesfamariam, "A review of multicriteria decision-making methods for infrastructure management," Structure and Infrastructure Engineering: Maintenance, Management, Life-Cycle Design and Performance, vol. 10, no. 9, pp. 1176-1210, 2014. 
[11] D. Jato-Espino, E. Castillo-Lopez, J. Rodriguez-Hernandez, and J. C. Canteras-Jordana, "A review of application of multicriteria decision making methods in construction," Automation in Construction, vol. 45, pp. 151-162, 2014.

[12] C. Kahraman, "Multi-criteria decision making methods and fuzzy sets," in Fuzzy Multi-Criteria Decision Making, C. Kahraman, Ed., vol. 16 of Springer Optimization and Its Applications, pp. 1-18, Springer, New York, NY, USA, 2008.

[13] J. Tamošaitiene and E. Gaudutis, "Complex assessment of structural systems used for high-rise buildings," Journal of Civil Engineering and Management, vol. 19, no. 2, pp. 305-317, 2013.

[14] E. Šiožinyte, J. Antuchevičiene, and V. Kutut, "Upgrading the old vernacular building to contemporary norms: multiple criteria approach," Journal of Civil Engineering and Management, vol. 20, no. 2, pp. 291-298, 2014.

[15] J. L. Hougaard and T. Baležentis, "Fuzzy efficiency without convexity," Fuzzy Sets and Systems, vol. 255, pp. 17-29, 2014.

[16] L. A. Zadeh, "Fuzzy set theory and probability theory: what is the relationship?" in International Encyclopedia of Statistical Science, pp. 563-566, Springer, 2014.

[17] D. Kelly and C. Smith, Bayesian Inference for Probabilistic Risk Assessment: A Practitioner's Guidebook, Springer, New York, NY, USA, 2011.

[18] J.-J. Wang, Y.-Y. Jing, C.-F. Zhang, and J.-H. Zhao, "Review on multi-criteria decision analysis aid in sustainable energy decision-making," Renewable and Sustainable Energy Reviews, vol. 13, no. 9, pp. 2263-2278, 2009.

[19] Y.-M. Wang and Y. Luo, "Integration of correlations with standard deviations for determining attribute weights in multiple attribute decision making," Mathematical and Computer Modelling, vol. 51, no. 1-2, pp. 1-12, 2010.

[20] C. Fu and Y. Wang, "An interval difference based evidential reasoning approach with unknown attribute weights and utilities of assessment grades," Computers and Industrial Engineering, vol. 81, pp. 109-117, 2015.

[21] E. Triantaphyllou and S. H. Mann, "An examination of the effectiveness of multi-dimensional decision-making methods: a decision-making paradox," International Journal of Decision Support Systems, vol. 5, no. 3, pp. 303-312, 1989.

[22] L. A. Zadeh, "Fuzzy sets," Information and Control, vol. 8, no. 3, pp. 338-353, 1965.

[23] P. J. M. van Laarhoven and W. Pedrycz, "A fuzzy extension of Saaty's priority theory," Fuzzy Sets and Systems, vol. 11, no. 3, pp. 229-241, 1983.

[24] C. Kahraman, S. C. Onar, and B. Oztaysi, "Fuzzy multicriteria decision-making: a literature review," International Journal of Computational Intelligence Systems, vol. 8, no. 4, pp. 637-666, 2015.

[25] E. K. Zavadskas, J. Antucheviciene, S. H. R. Hajiagha, and S. S. Hashemi, "Extension of weighted aggregated sum product assessment with interval-valued intuitionistic fuzzy numbers (WASPAS-IVIF)," Applied Soft Computing, vol. 24, pp. 10131021, 2014.

[26] S. H. Razavi Hajiagha, S. S. Hashemi, and E. K. Zavadskas, "A complex proportional assessment method for group decision making in an interval-valued intuitionistic fuzzy environment," Technological and Economic Development of Economy, vol. 19, no. 1, pp. 22-37, 2013.

[27] H.-C. Liu, X.-J. Fan, P. Li, and Y.-Z. Chen, "Evaluating the risk of failure modes with extended MULTIMOORA method under fuzzy environment," Engineering Applications of Artificial Intelligence, vol. 34, pp. 168-177, 2014.
[28] H.-C. Liu, J.-X. You, C. Lu, and Y.-Z. Chen, "Evaluating healthcare waste treatment technologies using a hybrid multi-criteria decision making model," Renewable and Sustainable Energy Reviews, vol. 41, pp. 932-942, 2015.

[29] H.-C. Liu, J.-X. You, Ch. Lu, and M.-M. Shan, "Application of interval 2-tuple linguistic MULTIMOORA method for healthcare waste treatment technology evaluation and selection," Waste Management, vol. 34, no. 11, pp. 2355-2364, 2014.

[30] T. Balezentis, S. Z. Zeng, and A. Balezentis, "MULTiMOORAIFN: a MCDM method based on intuitionistic fuzzy number for performance management," Economic Computation and Economic Cybernetics Studies and Research, vol. 48, no. 4, pp. 85-102, 2014.

[31] Z.-H. Li, "An extension of the MULTIMOORA method for multiple criteria group decision making based upon hesitant fuzzy sets," Journal of Applied Mathematics, vol. 2014, Article ID 527836, 16 pages, 2014.

[32] Z. Turskis and E. K. Zavadskas, "A new fuzzy additive ratio assessment method (ARAS-F). Case study: the analysis of fuzzy Multiple Criteria in order to select the logistic centers location," Transport, vol. 25, no. 4, pp. 423-432, 2010.

[33] M. Zamani, A. Rabbani, A. Yazdani-Chamzini, and Z. Turskis, "An integrated model for extending brand based on fuzzy ARAS and ANP methods," Journal of Business Economics and Management, vol. 15, no. 3, pp. 403-423, 2014.

[34] A. S. Ghadikolaei, S. K. Esbouei, and J. Antucheviciene, "Applying fuzzy MCDM for financial performance evaluation of Iranian companies," Technological and Economic Development of Economy, vol. 20, no. 2, pp. 274-291, 2014.

[35] N. Rikhtegar, N. Mansouri, A. A. Oroumieh, A. YazdaniChamzini, E. K. Zavadskas, and S. Kildiene, "Environmental impact assessment based on group decision-making methods in mining projects," Economic Research-Ekonomska Istraživanja, vol. 27, no. 1, pp. 378-392, 2014.

[36] M. Kabak, E. Köse, O. Kirilmaz, and S. Burmaoğlu, "A fuzzy multi-criteria decision making approach to assess building energy performance," Energy and Buildings, vol. 72, pp. 382-389, 2014.

[37] M. Kucukvar, S. Gumus, G. Egilmez, and O. Tatari, "Ranking the sustainability performance of pavements: an intuitionistic fuzzy decision making method," Automation in Construction, vol. 40, pp. 33-43, 2014.

[38] A. H. Azadnia, M. Z. M. Saman, and K. Y. Wong, "Sustainable supplier selection and order lot-sizing: an integrated multiobjective decision-making process," International Journal of Production Research, vol. 53, no. 2, pp. 383-408, 2015.

[39] S. M. Hashemian, M. Behzadian, R. Samizadeh, and J. Ignatius, "A fuzzy hybrid group decision support system approach for the supplier evaluation process," The International Journal of Advanced Manufacturing Technology, vol. 73, no. 5-8, pp. 11051117, 2014.

[40] M. K. Ghorabaee, M. Amiri, J. S. Sadaghiani, and G. H. Goodarzi, "Multiple criteria group decision-making for supplier selection based on COPRAS method with interval type-2 fuzzy sets," The International Journal of Advanced Manufacturing Technology, vol. 75, no. 5-8, pp. 1115-1130, 2014.

[41] S. Zeng, T. Balezentis, J. Chen, and G. Luo, "A projection method for multiple attribute group decision making with intuitionistic fuzzy information," Informatica, vol. 24, no. 3, pp. 485-503, 2013.

[42] S. M. Mousavi, B. Vahdani, R. Tavakkoli-Moghaddam, and N. Tajik, "Soft computing based on a fuzzy grey group compromise 
solution approach with an application to the selection problem of material handling equipment," International Journal of Computer Integrated Manufacturing, vol. 27, no. 6, pp. 547-569, 2014.

[43] A. Hadi-Vencheh and A. Mohamadghasemi, "A new hybrid fuzzy multi-criteria decision making model for solving the material handling equipment selection problem," International Journal of Computer Integrated Manufacturing, vol. 28, no. 5, pp. 534-550, 2015.

[44] S. Kiris, "Multi-criteria inventory classification by using a fuzzy analytic network process (ANP) approach," Informatica, vol. 24, no. 2, pp. 199-217, 2013.

[45] B. Bairagi, B. Dey, B. Sarkar, and S. Sanyal, "Selection of robot for automated foundry operations using fuzzy multicriteria decision making approaches," International Journal of Management Science and Engineering Management, vol. 9, no. 3, pp. 221-232, 2014.

[46] Ü. Kurt, "The fuzzy TOPSIS and generalized Choquet fuzzy integral algorithm for nuclear power plant site selection-a case study from Turkey," Journal of Nuclear Science and Technology, vol. 51, no. 10, pp. 1241-1255, 2014.

[47] E. K. Zavadskas, Z. Turskis, and V. Bagočius, "Multi-criteria selection of a deep-water port in the Eastern Baltic Sea," Applied Soft Computing Journal, vol. 26, pp. 180-192, 2014.

[48] W. Zhang, K. Sun, C. Lei, Y. Zhang, H. Li, and B. F. Spencer, "Fuzzy analytic hierarchy process synthetic evaluation models for the health monitoring of shield tunnels," Computer-Aided Civil and Infrastructure Engineering, vol. 29, no. 9, pp. 676-688, 2014.

[49] S. Avikal, R. Jain, and P. K. Mishra, "A Kano model, AHP and M-TOPSIS method-based technique for disassembly line balancing under fuzzy environment," Applied Soft Computing Journal, vol. 25, pp. 519-529, 2014.

[50] S. Avikal, P. K. Mishra, and R. Jain, "A fuzzy AHP and PROMETHEE method-based heuristic for disassembly line balancing problems," International Journal of Production Research, vol. 52, no. 5, pp. 1306-1317, 2014.

[51] C. H. Wang and H. S. Wu, "A novel framework to evaluate programmable logic controllers: a fuzzy MCDM perspective," Journal of Intelligent Manufacturing, 10 pages, 2014.

[52] T.-M. Yeh, F.-Y. Pai, and C.-W. Liao, "Using a hybrid MCDM methodology to identify critical factors in new product development," Neural Computing and Applications, vol. 24, no. 3-4, pp. 957-971, 2014.

[53] L. Anojkumar, M. Ilangkumaran, and V. Sasirekha, "Comparative analysis of MCDM methods for pipe material selection in sugar industry," Expert Systems with Applications, vol. 41, no. 6, pp. 2964-2980, 2014.

[54] C. Tan, W. H. Ip, and X. Chen, "Stochastic multiple criteria decision making with aspiration level based on prospect stochastic dominance," Knowledge-Based Systems, vol. 70, pp. 231-241, 2014.

[55] T. L. Saaty, "A scaling method for priorities in hierarchical structures," Journal of Mathematical Psychology, vol. 15, no. 3, pp. 234-281, 1977.

[56] L. G. Vargas, "Reciprocal matrices with random coefficients," Mathematical Modelling, vol. 3, no. 1, pp. 69-81, 1982.

[57] A. Saltelli, K. Chan, and E. M. Scott, Sensitivity Analysis, Wiley Series in Probability and Statistics, John Wiley \& Sons, New York, NY, USA, 2004.

[58] Y. Zhang, Z.-P. Fan, and Y. Liu, "A method based on stochastic dominance degrees for stochastic multiple criteria decision making," Computers and Industrial Engineering, vol. 58, no. 4, pp. 544-552, 2010.

[59] J. Ren, Y. Gao, and C. Bian, "Multiple criteria decision making based on discrete linguistic stochastic variables," Mathematical Problems in Engineering, vol. 2013, Article ID 546508, 11 pages, 2013.

[60] M. D. McKay, R. J. Beckman, and W. J. Conover, "A comparison of three methods for selecting values of input variables in the analysis of output from a computer code," Technometrics, vol. 21, no. 2, pp. 239-245, 1979.

[61] R. L. Iman and W. J. Conover, "Small sample sensitivity analysis techniques for computer models with an application to risk assessment," Communications in Statistics-Theory and Methods, vol. 9, no. 17, pp. 1749-1842, 1980.

[62] B. Möller and U. Reuter, Uncertainty Forecasting in Engineering, Springer, Berlin, Germany, 2007.

[63] A. Saltelli, M. Ratto, T. Andres et al., Global Sensitivity Analysis: the Primer, John Wiley \& Sons, Chichester, UK, 2008.

[64] A. Saltelli, S. Tarantola, F. Campolongo, and M. Ratto, Sensitivity Analysis in Practice: A Guide to Assessing Scientific Models, John Wiley \& Sons, Chichester, UK, 2004.

[65] A. Ligmann-Zielinska, "Spatially-explicit sensitivity analysis of an agent-based model of land use change," International Journal of Geographical Information Science, vol. 27, no. 9, pp. 1764-1781, 2013.

[66] A. Ligmann-Zielinska and P. Jankowski, "Spatially-explicit integrated uncertainty and sensitivity analysis of criteria weights in multicriteria land suitability evaluation," Environmental Modelling \& Software, vol. 57, pp. 235-247, 2014.

[67] C.-R. Wu, C.-T. Lin, and H.-C. Chen, "Optimal selection of location for Taiwanese hospitals to ensure a competitive advantage by using the analytic hierarchy process and sensitivity analysis," Building and Environment, vol. 42, no. 3, pp. 14311444, 2007.

[68] A. Awasthi, S. S. Chauhan, and S. K. Goyal, "A multi-criteria decision making approach for location planning for urban distribution centers under uncertainty," Mathematical and Computer Modelling, vol. 53, no. 1-2, pp. 98-109, 2011.

[69] J. Malczewski and C. Rinner, Multicriteria Decision Analysis in Geographic Information Science, Springer, New York, NY, USA, 2015.

[70] A. Shanian and O. Savadogo, "A methodological concept for material selection of highly sensitive components based on multiple criteria decision analysis," Expert Systems with Applications, vol. 36, no. 2, pp. 1362-1370, 2009.

[71] G. Büyüközkan and G. Çifçi, "A novel fuzzy multi-criteria decision framework for sustainable supplier selection with incomplete information," Computers in Industry, vol. 62, no. 2, pp. 164-174, 2011.

[72] E. Triantaphyllou and A. Sánchez, "A sensitivity analysis approach for some deterministic multi-criteria decisionmaking methods," Decision Sciences, vol. 28, no. 1, pp. 151-194, 1997.

[73] E. Triantaphyllou, Multi-Criteria Decision Making: A Comparative Study, Kluwer Academic Publishers, Dordrecht, The Netherlands, 2000.

[74] M. Bevilacqua and M. Braglia, "The analytic hierarchy process applied to maintenance strategy selection," Reliability Engineering and System Safety, vol. 70, no. 1, pp. 71-83, 2000.

[75] C.-W. Chang, C.-R. Wu, C.-T. Lin, and H.-C. Chen, "An application of AHP and sensitivity analysis for selecting the best 
slicing machine," Computers \& Industrial Engineering, vol. 52, no. 2, pp. 296-307, 2007.

[76] D. Choudhary and R. Shankar, "An STEEP-fuzzy AHP-TOPSIS framework for evaluation and selection of thermal power plant location: a case study from India," Energy, vol. 42, no. 1, pp. 510521, 2012.

[77] A. Awasthi, S. S. Chauhan, H. Omrani, and A. Panahi, "A hybrid approach based on SERVQUAL and fuzzy TOPSIS for evaluating transportation service quality," Computers \& Industrial Engineering, vol. 61, no. 3, pp. 637-646, 2011.

[78] A. Awasthi, S. S. Chauhan, and H. Omrani, "Application of fuzzy TOPSIS in evaluating sustainable transportation systems," Expert Systems with Applications, vol. 38, no. 10, pp. 1227012280, 2011.

[79] A. Awasthi and S. S. Chauhan, "A hybrid approach integrating Affinity Diagram, AHP and fuzzy TOPSIS for sustainable city logistics planning," Applied Mathematical Modelling, vol. 36, no. 2, pp. 573-584, 2012.

[80] M. Saisana, A. Saltelli, and S. Tarantola, "Uncertainty and sensitivity analysis techniques as tools for the quality assessment of composite indicators," Journal of the Royal Statistical Society Series A: Statistics in Society, vol. 168, no. 2, pp. 307-323, 2005.

[81] D. Ben-Arieh, "Sensitivity of multi-criteria decision making to linguistic quantifiers and aggregation means," Computers and Industrial Engineering, vol. 48, no. 2, pp. 289-309, 2005.

[82] G. Büyüközkan and G. Çifçi, "A combined fuzzy AHP and fuzzy TOPSIS based strategic analysis of electronic service quality in healthcare industry," Expert Systems with Applications, vol. 39, no. 3, pp. 2341-2354, 2012.

[83] M. Zarghami, "Soft computing of the Borda count by fuzzy linguistic quantifiers," Applied Soft Computing Journal, vol. 11, no. 1, pp. 1067-1073, 2011.

[84] M. Zarghami and F. Szidarovszky, "On the relation between compromise programming and ordered weighted averaging operator," Information Sciences, vol. 180, no. 11, pp. 2239-2248, 2010.

[85] E. R. Vaidogas, E. K. Zavadskas, and Z. Turskis, "Reliability measures in multicriteria decision making as applied to engineering projects," International Journal of Management and Decision Making, vol. 8, no. 5-6, pp. 497-518, 2007.

[86] B. J. Garrick, Quantifying and Controlling Catastrophic Risks, Elsevier, Amsterdam, The Netherlands, 2008.

[87] L. F. Gay and S. K. Sinha, "Resilience of civil infrastructure systems: literature review for improved asset management," International Journal of Critical Infrastructures, vol. 9, no. 4, pp. 330-350, 2013.

[88] B. J. Jennings, E. D. Vugrin, and D. K. Belasich, "Resilience certification for commercial buildings: a study of stakeholder perspectives," Environment Systems and Decisions, vol. 33, no. 2, pp. 184-194, 2013.

[89] G. Lizarralde, K. Chmutina, L. Bosher, and A. Dainty, "Sustainability and resilience in the built environment: the challenges of establishing a turquoise agenda in the UK,' Sustainable Cities and Society, vol. 15, pp. 96-104, 2015.

[90] M. Rausand, Reliability of Safety-Critical Systems: Theory and Applications, Wiley, Chichester, UK, 2014.

[91] E. R. Vaidogas and E. K. Zavadskas, "Introducing reliability measures into multi-criteria decision making," International Journal of Management and Decision Making, vol. 8, no. 5-6, pp. 475-496, 2007.
[92] N. D. Singpurwalla, Reliability and Risk. A Bayesian Perspective, Wiley, Chichester, UK, 2006.

[93] E. R. Vaidogas, "On applying sparse and uncertain information to estimating the probability of failure due to rare abnormal situations," Information Technology and Control, vol. 38, no. 2, pp. 135-146, 2009.

[94] J. C. Helton and W. L. Oberkampf, "Alternative representations of epistemic uncertainty," Reliability Engineering \& System Safety, vol. 85, no. 1-3, pp. 1-10, 2004.

[95] C. J. Roy and W. L. Oberkampf, "A comprehensive framework for verification, validation, and uncertainty quantification in scientific computing," Computer Methods in Applied Mechanics and Engineering, vol. 200, no. 25-28, pp. 2131-2144, 2011.

[96] M. C. M. Troffaes, G. Walter, and D. Kelly, "A robust Bayesian approach to modeling epistemic uncertainty in common-cause failure models," Reliability Engineering and System Safety, vol. 125, no. 1, pp. 13-21, 2014.

[97] E. K. Zavadskas and E. R. Vaidogas, "Multiattribute selection from alternative designs of infrastructure components for accidental situations," Computer-Aided Civil and Infrastructure Engineering, vol. 24, no. 5, pp. 346-358, 2009.

[98] S. Mannan, Ed., Lees's Loss Prevention in the Process Industries, Elsevier, Amsterdam, The Netherlands, 2005.

[99] E. Versluis, M. van Asselt, T. Fox, and A. Hommels, "The EU Seveso regime in practice: from uncertainty blindness to uncertainty tolerance," Journal of Hazardous Materials, vol. 184, no. 1-3, pp. 627-631, 2010.

[100] L. T. Ostrom and C. A. Wilhelmsen, Risk Assessment. Tools, Techniques, and Their Applications, Wiley, Hoboken, NJ, USA, 2012.

[101] E. R. Vaidogas and J. Šakènaite, "Protecting built property against fire disasters: multi-attribute decision making with respect to fire risk," International Journal of Strategic Property Management, vol. 14, no. 4, pp. 391-407, 2010.

[102] J.-L. Zhou, Z.-H. Bai, and Z.-Y. Sun, "A hybrid approach for safety assessment in high-risk hydropower-constructionproject work systems," Safety Science, vol. 64, pp. 163-172, 2014.

[103] M. D. Catrinu and D. E. Nordgård, "Integrating risk analysis and multi-criteria decision support under uncertainty in electricity distribution system asset management," Reliability Engineering \& System Safety, vol. 96, no. 6, pp. 663-670, 2011.

[104] A. Nieto-Morote and F. Ruz-Vila, "A fuzzy approach to construction project risk assessment," International Journal of Project Management, vol. 29, no. 2, pp. 220-231, 2011.

[105] A. Nieto-Morote and F. Ruz-Vila, "A fuzzy multi-criteria decision-making model for construction contractor prequalification," Automation in Construction, vol. 25, pp. 8-19, 2012.

[106] Y. Xiang, C. Liu, K. Zhang, and Q. Wu, "Risk analysis and management of submerged floating tunnel and its application," Procedia Engineering, vol. 4, pp. 107-116, 2010.

[107] Y.-M. Wang, J. Liu, and T. M. S. Elhag, "An integrated AHPDEA methodology for bridge risk assessment," Computers \& Industrial Engineering, vol. 54, no. 3, pp. 513-525, 2008.

[108] M. S. El-Abbasy, T. Zayed, M. Ahmed, H. Alzraiee, and M. Abouhamad, "Contractor selection model for highway projects using integrated simulation and analytic network process," Journal of Construction Engineering and Management, vol. 139, no. 7, pp. 755-767, 2013.

[109] L. Hui, W. Yongqing, S. Shimei, and S. Baotie, "Study on safety assessment of fire hazard for the construction site," Procedia Engineering, vol. 43, pp. 369-373, 2012. 
[110] M. A. Alqassim and N. N. Daeid, "Fires and related incidents in Dubai, United Arab Emirates (2006-2013)," Case Studies in Fire Safety, vol. 2, pp. 28-36, 2014.

[111] D. J. Rasbash, G. Ramachandran, B. Kandola, J. M. Watts, and M. Law, Evaluation of Fire Safety, John Wiley \& Sons, Chichester, UK, 2004.

[112] C. M. Zhao, S. M. Lo, J. A. Lu, and Z. Fang, "A simulation approach for ranking of fire safety attributes of existing buildings," Fire Safety Journal, vol. 39, no. 7, pp. 557-579, 2004.

[113] J. Wong, H. Li, and J. Lai, "Evaluating the system intelligence of the intelligent building systems-part 1: development of key intelligent indicators and conceptual analytical framework," Automation in Construction, vol. 17, no. 3, pp. 284-302, 2008.

[114] J. Wong, H. Li, and J. Lai, "Evaluating the system intelligence of the intelligent building systems. Part 2: construction and validation of analytical models," Automation in Construction, vol. 17, no. 3, pp. 303-321, 2008.

[115] E. R. Vaidogas and J. Šakènaite, "Multi-attribute decisionmaking in economics of fire protection," Engineering Economics, vol. 22, no. 3, pp. 262-270, 2011.

[116] E. R. Vaidogas and L. Linkute, "Sitting the barrier aimed at protecting roadside property from accidental fires and explosions on road: a pre-optimisation stage," The Baltic Journal of Road and Bridge Engineering, vol. 7, no. 4, pp. 277-287, 2012.

[117] E. K. Zavadskas and J. Antucheviciene, "Multiple criteria evaluation of rural building's regeneration alternatives," Building and Environment, vol. 42, no. 1, pp. 436-451, 2007.

[118] E. Krygiel and B. Nies, Green BIM: Successful Sustainable Design with Building Information Modeling, Wiley, Indianapolis, Ind, USA, 2008.

[119] AIA, Guide, Instructions and Commentary to the 2013 AIA Digital Practice Documents, The American Institute of Architects, Washington, DC, USA, 2013.

[120] B. A. Wayland, Security for Business Professionals. How to Plan, Implement, and Manage your Company's Security Program, Elsevier, Amsterdam, The Netherlands, 2014.

[121] D. Drengenberg and G. Corley, "Evolution of building code requirements in a post 9/11 world," CTBUH Journal, no. 3, pp. 32-35, 2011 


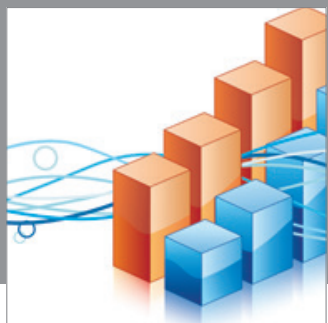

Advances in

Operations Research

mansans

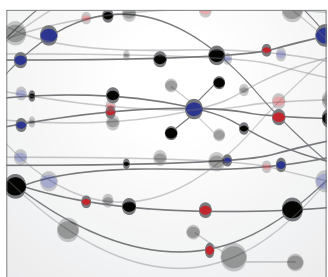

The Scientific World Journal
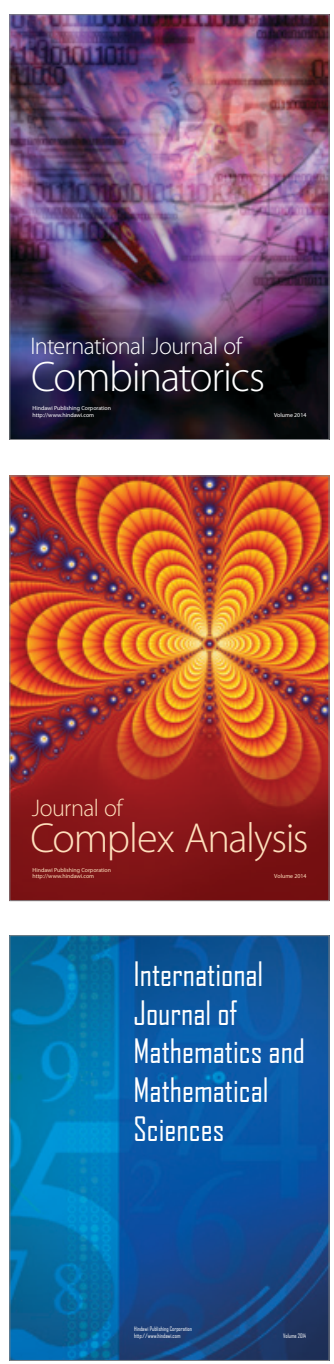
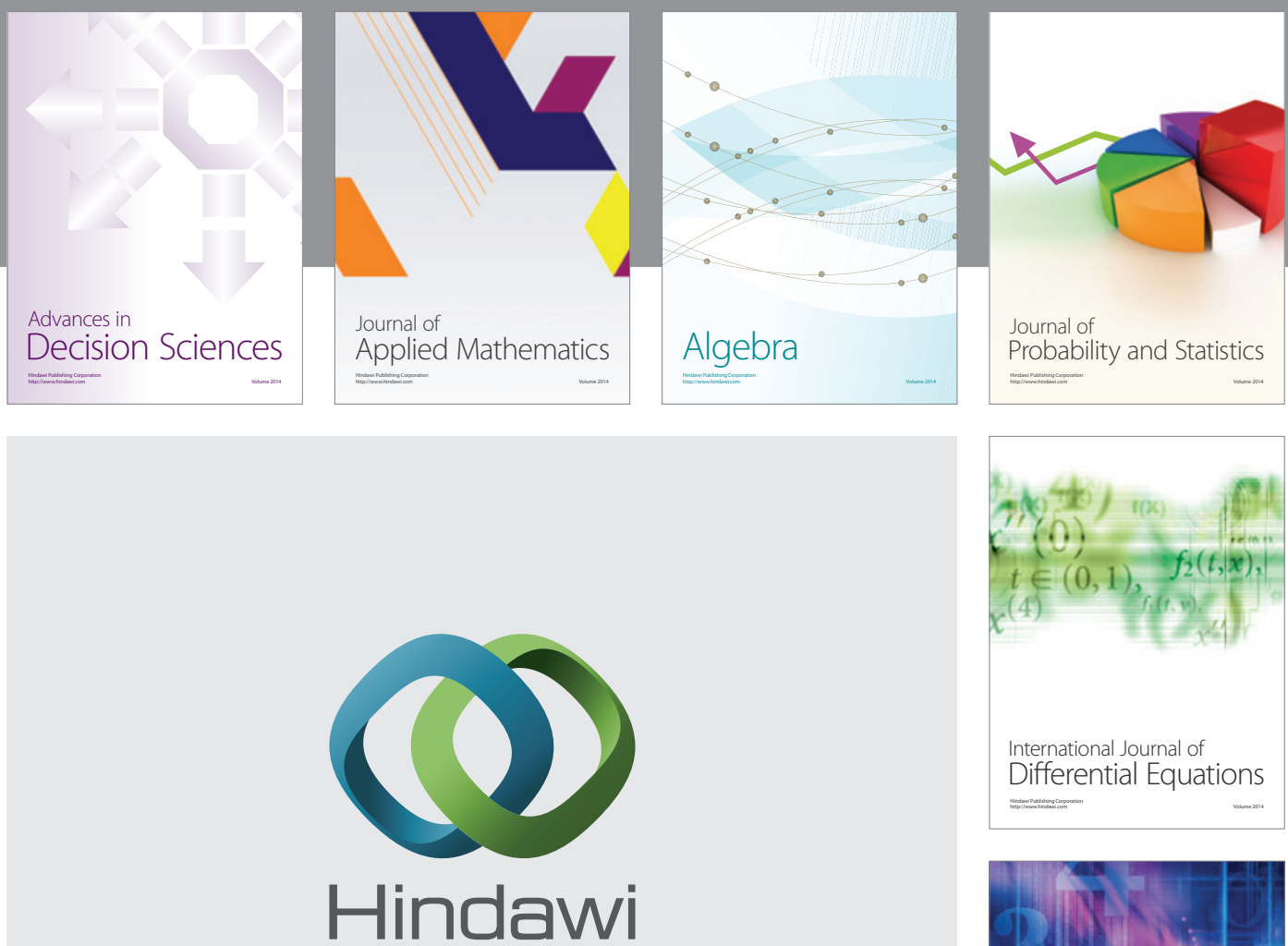

Submit your manuscripts at http://www.hindawi.com
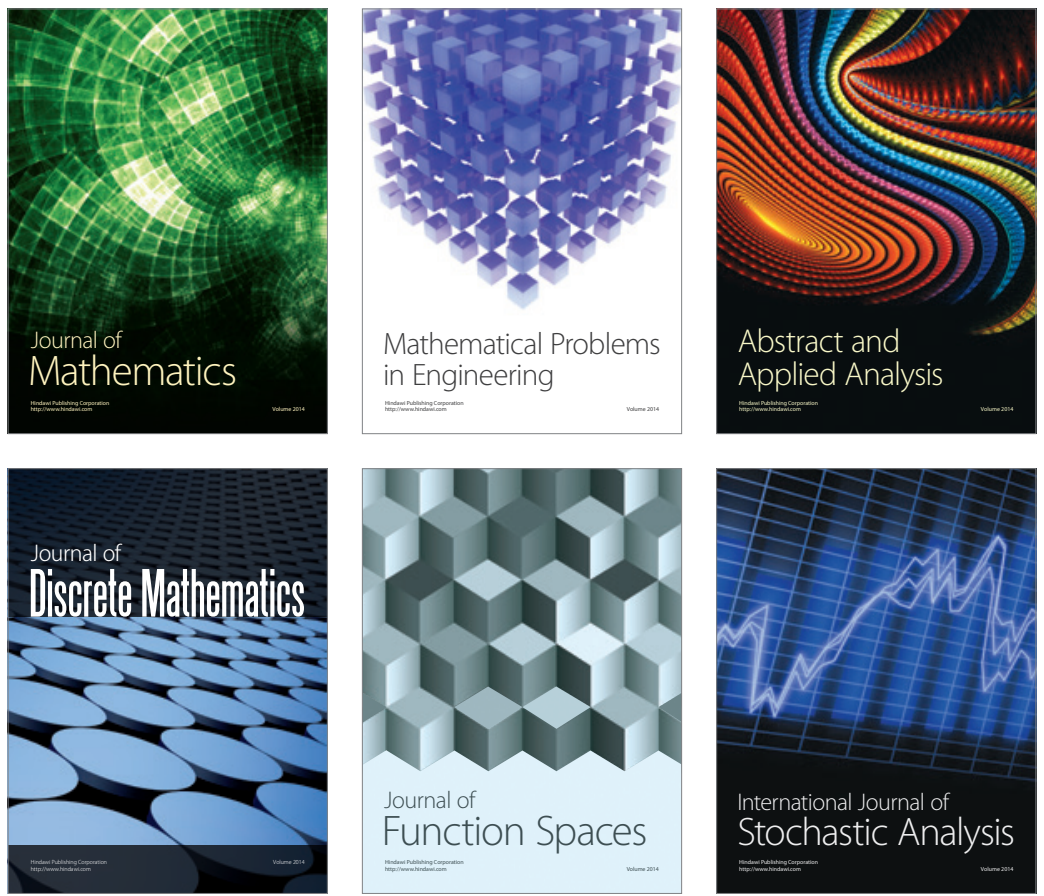

Journal of

Function Spaces

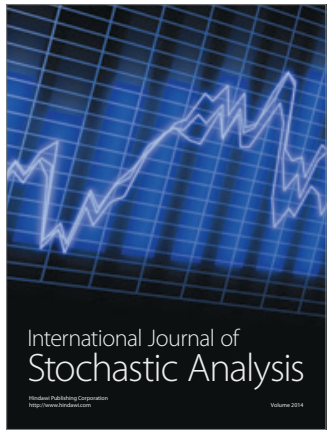

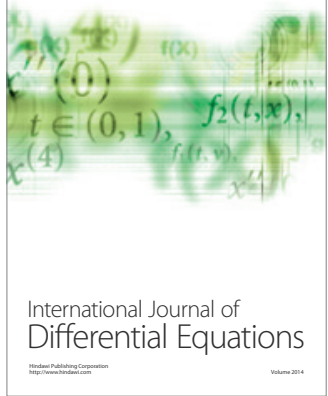
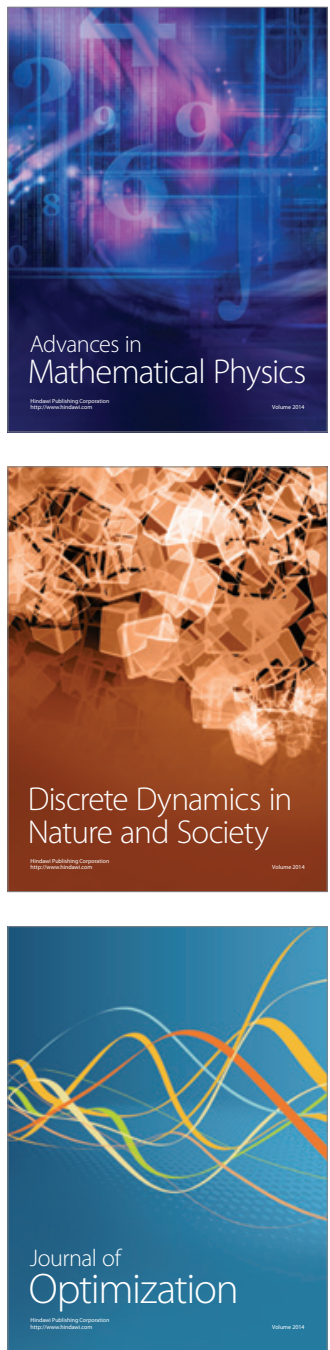